\title{
Impacts of Global Warming on Meiyu-Baiu Extreme Rainfall and Associated Mid-Latitude Synoptic-Scale Systems as Inferred From 20km AGCM Simulations
}

Ka Wai So ( $1155031409 @$ link.cuhk.edu.hk)

The Chinese University of Hong Kong Faculty of Science https://orcid.org/0000-0002-7435-0631

Chi-Yung Tam

The Chinese University of Hong Kong

Ngar-Cheung Lau

The Chinese University of Hong Kong

\section{Research Article}

Keywords: Global Warming, Synoptic-scale, Clausius-Clapeyron

Posted Date: April 13th, 2021

DOI: https://doi.org/10.21203/rs.3.rs-383898/v1

License: (1) This work is licensed under a Creative Commons Attribution 4.0 International License.

Read Full License

Version of Record: A version of this preprint was published at Climate Dynamics on January 14th, 2022. See the published version at https://doi.org/10.1007/s00382-021-06072-5. 


\section{Abstract}

The impacts of global warming on Meiyu-Baiu extreme rainfall and the associated mid-latitude synopticscale weather systems over the Eastern China (EC) and the Baiu rainband (Bu) regions in East Asia have been examined, based on simulations from the 20-km Meteorological Research Institute atmospheric general circulation model (MRI-AGCM3.2S). This model was demonstrated to give realistic Asian extreme rainfall, when compared with data from the Tropical Rainfall Measuring Mission (TRMM). Here we used a novel wave-selection algorithm based on the $300 \mathrm{hPa}$ wind, in order to identify upper-level propagating wave signals in conjunction with the occurrence of extreme precipitation in either EC or Bu. The same algorithm was applied for both the present (1979-2003) and future (2075-2099) climate simulations from the AGCM, so as to infer the impacts of global warming on the behavior of these systems. Results show robust decrease of intensity of systems influencing both Bu and EC in the future warmer climate. Their corresponding low-to-mid level circulation, as revealed by vertical velocity, temperature advection and sealevel pressure composites, was also found to be weakened. This is likely related to changes in the background circulation in future over the East Asian mid-latitude zone, such as the widespread increment of the seasonal mean static stability at $500 \mathrm{hPa}$. However, the wave-associated precipitation over these regions was enhanced in the future climate simulations. This can be attributed to more strong intensity rainfall, which increases as the background temperature in these regions warms, largely following the Clausius-Clapeyron relation. Therefore, changes of wave-related extreme precipitation in EC and Bu are mainly controlled by the thermodynamic effect; the latter appears to be much stronger than the potential impacts due to the slight weakening of these weather systems.

\section{Introduction}

The development of the summer monsoon in East Asia is characterised by large-scale reversal in the lowlevel winds, together with northward advancement of a monsoon rain belt (see, e.g., Wang and Lin, 2002). After rainfall surges over South China Sea in mid-May, the rain belt undergoes an abrupt northward jump, leading to the initiation of the Meiyu-Baiu season in early to mid-June (Ding and Chan, 2005). The latter is also the major rainy season covering peaks of precipitation over Yangtze River-Huaihe River basin (Ding et al., 2007) and southwestern Japan (Ninomiya and Akiyama, 1992; Ding and Sikka, 2006). On the synoptic scale, low-pressure troughs associated with significant horizontal wind shear can bring prolonged heavy rainfall in the rainband vicinity. Although Meiyu (over China) and Baiu (over Japan) occur almost concurrently in early summer, they exhibit rather different dynamical features (Ding, 1992; Ding et al., 2007; Ninomiya and Shibagaki, 2007; Sampe and Xie, 2010). For instance, Chen and Chang (1980) indicated that while disturbances over southern East China Sea and southern Japan resemble typical midlatitude baroclinic frontal systems, those over southeastern China resemble semi-tropical disturbances.

Observations show that extreme precipitation over most parts of the globe has intensified in the past few decades (Alexander et al. 2006; Donat et al., 2013; Westra et al., 2013; Donat et al., 2016). Such general intensification is projected to continue in the future according to model simulations (Sillmann et al., 2013; 
Donat et al., 2016). It is believed that extreme rainfall scales according to the Clausius-Clapeyron (CC) relation (e.g., Pall et al., 2007), whereas the increase in the mean precipitation is less rapid and constrained by the global energy budget (Allen and Ingram, 2002; Sillmann et al., 2013). However, superCC scaling for change of rainfall extreme is reported over Europe (Lenderink and van Meijgaard, 2008), which indicates the possible influences due to other mechanisms such as dynamical effect of weather systems. Over East Asia, a variety of weather systems, such as tropical cyclones (TCs), wintertime extratropical storms that bring extreme precipitation are influenced by global warming (Hawcroft et al., 2012; Wang et al., 2006; Ulbrich et al., 2009; Mizuta et al., 2011; Utsumi et al., 2016; Lui et al., 2018). However, relatively few studies focused on how the characteristics of summertime synoptic-scale system might change due to warming background (e.g., Geng and Sugi, 2002). Coumou et al. (2015) studied summertime synoptic-scale wave activity and its projected change under global warming; they found that total eddy kinetic energy of those synoptic-scale waves decreases mainly due to weakening of vertical wind shear and zonal-mean flow. Instead, Li et al. (2021) focused on the East Asian summer monsoonal front, and they found that the associated regional precipitation intensifies in the future climate. However, in-depth analyses on the synoptic-scale systems associated with extreme rainfalls are still very limited (e.g., Francis and Vavrus, 2012; Röthlisberger et al., 2016).

Motivated by the above reasons, and following up the recent study of Lui et al. (2018), this study investigate how Meiyu-Baiu extreme rainfall over Eastern China (EC) and Baiu rainband (Bu) regions, and their associated mid-latitude synoptic-scale systems change in the future climate, based on projections from the 20-km Meteorological Research Institute (MRI) atmospheric general circulation model (AGCM) (hereinafter referred to as MRI-AGCM3.2S). We will examine how much the dynamical change of midlatitude synoptic systems is related to the change of rainfall extremes over east Asia, and therefore revealing the relative importance between thermodynamic and dynamical effects on modulating rainfall extremes. EC and Bu regions are chosen for the analysis because they are strongly influenced by transient eddies within the westerlies during the characteristic Meiyu-Baiu rainy season (e.g., Ninomiya and Shibagaki, 2007; Sampe and Xie, 2010). Moreover, since the geographical location and frontal structure of Meiyu and Baiu are quite different, studying both regions allows us to further examine how these systems and related rainfall might response differently to global warming. The remainder of this paper is organized as follows. Section 2 introduces the data and methodology. Section 3 evaluates the performance of the AGCM in capturing extreme precipitation characteristics and projections of earlysummer extreme precipitation. Section 4 examines changes in Meiyu-Baiu extreme rainfall and the associated synoptic-scale systems. Discussions and conclusions are given in Section 5.

\section{Data And Methodology}

\subsection{AGCM experiments}

MRI-AGCM3.2S is an improved version of a global model jointly developed by Japan Meteorological Agency (JMA) and Meteorological Research Institute (MRI) (Mizuta et al., 2006; Kitoh et al., 2009). It is a global, hydrostatic primitive-equation model with a horizontal grid size of about $20 \mathrm{~km}$ with unevenly 
spaced vertical levels reaching $0.01 \mathrm{hPa}$. Various parameterization schemes, such as Yoshimura cumulus scheme (Yukimoto et al., 2011), Tiedtke cloud scheme (Tiedtke, 1993) and the radiation scheme used in JMA operational model (JMA, 2007), are introduced for improving climate simulations. A comprehensive description and evaluation of the model were given by Mizuta et al. (2012). The present climate (19792003) simulation was carried out by using monthly-mean sea surface temperature (SST) and sea-ice concentration (SIC) observations from the Met Office Hadley Centre (Rayner et al., 2003). The future climate (2075-2099) was simulated by superimposing SST and SIC with projected changes generated by eighteen models from the Coupled Model Intercomparison Project phase 3 (CMIP3) (Solomon et al., 2007), under the Special Report on Emissions Scenarios (SRES) A1B scenario, as the prescribed lower boundary conditions (Murakami et al., 2012).

\subsection{Observations and reanalysis data}

The Tropical Rainfall Measuring Mission 3B42 version 7 (TRMM3B42v7) (Huffman et al., 2007) data, produced by combination of satellite-based precipitation estimates and rain gauge-based adjustment, were chosen for comparison with rainfall simulations. TRMM covers the latitudinal band between $50 \mathrm{~N}$ and 50 S since 1998 , at relatively fine scales $\left(0.25^{\circ} \times 0.25^{\circ}, 3\right.$ hourly). Zhao and Yatagai (2014) found that previous version of TRMM3B42 is generally consistent in representing the spacetime rainfall characteristics over China. Although it underestimates (overestimates) light and moderate (heavy) precipitation in western (southeastern) China, the capability of this version in capturing precipitation has been improved (Chen et al., 2013). Best track data from the Joint Typhoon Warning Center (JTWC) was also used to distinguish between tropical cyclone (TC) and non-TC rainfall. Meanwhile, upper-air meteorological variables from the European Centre for Medium-Range Weather Forecasts (ECMWF) reanalysis (ERA)-Interim data at $0.75^{\circ} \times 0.75^{\circ}$ resolution were also used (Dee et al., 2011). Unless specified otherwise, daily mean values of ERA-Interim reanalysis data are used in this study.

\subsection{Time filtering and Identification of upper-level waves}

To represent mid-latitude upper-level transient waves, we focus on the anomalous $300 \mathrm{hPa}$ v-wind (v300') signals (see Chang (1993); Chang and Yu (1999)). Although bandpass filtering is frequently adopted in extracting synoptic-scale variations, it tends to remove signals outside the specified frequency band, tampering the temporal evolution of waves (Trenberth, 1991; Chang, 1993; Berbery and Vera, 1996; Chang and $\mathrm{Yu}, 1999)$. Here the anomalous signal is defined simply as the value of a variable after the removal of the June-to-mid-July mean, computed for a particular year ${ }^{[1]}$. Note that the interannual variability in the seasonal mean has been removed by construction.

An extreme precipitation event (extreme case) was first identified whenever the daily precipitation exceeds the $95^{\text {th }}$ percentile (R95p), based on statistics during wet days (i.e. days when daily rainfall $>0.1 \mathrm{~mm}$ ). All the extreme cases related to TCs were discarded, with TC rainfall defined following Lui et al. (2018; see also Murakami et al. (2012)). Next, a novel wave-selection algorithm was developed to identify upperlevel synoptic-scale waves associated with non-TC extreme rainfall. A schematic diagram for wave 
identification, showing the upper-level trough relative to the extreme rainfall case location, is given by Fig. 1. By inspecting circulation composites related to extreme rain days, it was found that extreme rainfall cases are likely to be associated with an upper-level trough west of the search region, with wavelength of $\sim 45^{\circ}$ (figures not shown). Therefore, a rectangular selection domain was designed with longitudinal extent of $22^{\circ}$, so that at least half of the wave pattern can be captured. The meridional width of the domain was set to be $10^{\circ}$. In fact, wave spectra of $v 300^{\prime}$, from 60 to $150^{\circ} \mathrm{E}$, showed that signals with wavelength of $45^{\circ}$ give the greatest variance within the band of 30 to $40^{\circ} \mathrm{N}$ (figures not shown). Three criteria, as listed below, were then applied to 6-hourly $\mathrm{v} 300^{\prime}$ data to determine whether an upper-level travelling trough exists within the selection domain:

1. $v 300_{6 h r}$ ' being positive over at least $25 \%$, and negative over at least another $25 \%$ of the area of the selection domain, at any synoptic hour (i.e. 00, 06, 12, 18UTC);

2. Mean longitude of positive $v 300_{6 \mathrm{hr}}$ ' greater than that of negative $\mathrm{v} 300_{6 \mathrm{hr}}{ }^{\prime}$ by at least $5.5^{\circ}$ at any synoptic hour; and

3. Change of $\mathrm{v}^{300_{6 h r}}$ ' from positive to negative, from 00UTC to $18 \mathrm{UTC}$, covering at least 11 (9) \% of area of selection domain for $\mathrm{EC}(\mathrm{Bu})$ region.

The first criterion requires that there are both negative and positive $\mathrm{v}^{300_{6 \mathrm{hr}}}$ 'signals in the domain, consistent with the presence of a pressure trough. For a perfectly sinusoidal wave, positive and negative signals should occupy $50 \%$ of the domain; the threshold of $25 \%$ is used to accommodate for non-ideal situations. The second criterion ensures that $\mathrm{v}^{300_{6 h}}$ ' gives a wave-like signal, with half wavelength of $5.5^{\circ}$ or more. Finally, the third criterion examines whether the trough signal is propagating eastward. The threshold value 11 (9) \% for EC (Bu) indicates the portion of area where $v 300_{6 h}$ ' changes sign from positive to negative in one day. The values were based on estimated phase speed of upper-level disturbances $6.5^{\circ}\left(5.0^{\circ}\right)$ eastward per day for those affecting EC $(\mathrm{Bu})$; the threshold value is set by considering half of such phase speed, so that the majority of propagating short waves are expected to fulfil this criterion. (Note that we have also explored the use of the relative vorticity; however, this variable is noisier and hence more difficult to use.)

Sensitivity of our results to the relative position between the extreme rainfall location and selection domain was also examined (see Fig. S1). It was found that, when the selection domain was located northwest of the extreme case location, both the fraction of cases satisfying all three criteria, and the domain averaged wave activity were found to be the largest (see Figs. S1b and S1c). Hereafter, extreme rainfall cases, with $\mathrm{v}^{300_{6 h r}}$ in the northwestward domain satisfying all three selection criteria, are referred to as "wave-related extreme rainfall cases". (The remaining extreme rainfall cases are likely to be associated with other weather systems and thus not of our interest.)

Since the wave-related extreme rainfall days are likely to be serially related, "clusters" of extreme rain days need to be identified, to avoid over counting in subsequent composite analyses. At any geographical 
location, a cluster is defined as a series of consecutive days during which there were wave-related extreme rainfall cases.

A cluster would be further split into two if the average longitude of cases decreases more than $6^{\circ}\left(8^{\circ}\right)$ for $\mathrm{EC}(\mathrm{Bu})$ region (i.e., half of the longitudinal extent of search region). It could separate the series of days into clusters each of which correspond to only one travelling wave only. For each cluster, the day with maximum regional mean precipitation is defined as "day 0"; lag composites (from -2 days to +2 days) are computed. We also apply the wave-selection algorithm to observations (TRMM precipitation dataset and JTWC best track data) and ERA-interim reanalysis data. Composite maps for upper-level waves based on model runs and observational/reanalysis datasets are generally consistent with each other (see Figs. $6 a, 6 b$ and S2). The algorithm using the same threshold values and for the NW selection box was also adopted for future climate projections, so as to infer impacts of global warming on the extreme rainfall and the associated wave systems.

${ }^{[1]}$ We also conducted analyses based on 2.5-to-6-day bandpass filtered anomalies. Bandpass filtering in general led to weaker signals; otherwise the results are qualitatively similar to those to be presented in subsequent sections.

\section{Present Climate Simulations And Projected Changes Of Extreme Precipitation}

To examine the capability of the AGCM in reproducing realistic extreme precipitation over the East Asian monsoon region, its characteristics based on its present climate simulations are first evaluated. Figs. 2 and 3 show the climatological decad mean precipitation and probability of occurrence of extreme cases from $13^{\text {th }}$ ( 1 May $\left.-10 \mathrm{May}\right)$ to $21^{\text {st }}$ decad $(20 \mathrm{Jul}-29 \mathrm{Jul})$, based on TRMM and model simulations, respectively. Here the decad-mean probability is computed by dividing the count of extreme cases by the total number of days for each decad. From Fig. 2, it can be seen that extreme cases become more frequent from the $15^{\text {th }}$ ( 21 May -30 May) to $17^{\text {th }}$ decad (10 Jun -19 Jun) over southeastern China to southern Japan due to frontal activities. An abrupt increase of occurrences is seen over northern South China Sea in the $14^{\text {th }}$ decad, followed by the formation and northward moment of a band-shaped region comprising strong activities, from eastern China to south of Japan. The AGCM also gives a similar northward moving cluster of extreme rainfall events, although activities over eastern China and Japan appear to be disjoined (see Fig. 3). The strong activity band reaches its northern-most position around the $19^{\text {th }}$ and $20^{\text {th }}$ decad ( $30 \mathrm{Jun}-9 \mathrm{Jul}$ and $10 \mathrm{Jul}-19 \mathrm{Jul}$ ); this is also captured in the model simulations (Fig. 3). From the $20^{\text {th }}$ decad, very few extreme cases are found in either TRMM or model data over this region. Finally, the commencement, northward movement and end of Meiyu-Baiu precipitation corresponds well with the evolution of extremes (Fig. 2). This is also captured by the AGCM, although the simulated total precipitation over eastern China is slightly overestimated before $17^{\text {th }}$ decad. In general, the Meiyu-Baiu rainband evolution, together with the accompanying heavy rainfall for the EC (25-32N, $108-120 \mathrm{E})$ and $\mathrm{Bu}(30-35 \mathrm{~N}, 127-143 \mathrm{E})$ regions, are broadly reproduced in the model environment. 
Fig. 4 shows the deviation of probability of occurrence of extreme rainfall cases from the annual mean, averaged over the two regions. Based on TRMM data, there is high probability of occurrence over EC from $11^{\text {th }}$ to $21^{\text {st }}$ decad, with a maximum in $17^{\text {th }}$ to $18^{\text {th }}$ decads (Fig. 4a). Model simulated extremes tend to occur from $7^{\text {th }}$ to $18^{\text {th }}$ decads, with a relatively broad peak from $10^{\text {th }}$ to $16^{\text {th }}$ decad (Fig. $4 \mathrm{c}$ ). This might be related to overestimated springtime rainfall in the EC region. For Bu, both observations and model simulations show the highest probability from $16^{\text {th }}$ to $19^{\text {th }}$ decad, followed by a secondary peak around $25^{\text {th }}$ to $28^{\text {th }}$ decad (Figs. $4 \mathrm{~b}$ and $4 \mathrm{~d}$ ). The above indicates that the heaviest precipitation in these regions is associated with the northward passage of the Meiyu-Baiu rainband from June to mid-July. Hereinafter, we will focus on rainfall extremes within period of June 1 to July 15 , which will be referred to as the Meiyu-Baiu season.

Before inspecting the associated synoptic-scale systems, projected changes of Asia/western north Pacific extreme rainfall, according to various metrics, are briefly examined. Fig. 5 shows changes of the Simple Daily Intensity Index (SDIl; defined as accumulated rainfall averaged over wet days only) and R95p during the Meiyu-Baiu season, in the future compared to the present climate. Over the latitudinal band of about 20-35N (from 90 to 150E), the amplitudes of strongest signals are significantly enhanced. This is sandwiched by two broad regions with suppressed signals, with one extending from northern China, Korea and around the northern Japan, and the other of from northern part of the South China Sea to east of the Philippines. Such region of enhanced rainfall is generally consistent with the summertime rainfall change projected by Oh et al. (2014), although there still exists large uncertainties of the position of enhanced precipitation among different models. Since the longitudinal extent of westerlies and subtropical high-pressure belt is generally much larger than their meridional width, such sandwiched patterns of signals may be related to projected changes of those large-scale circulation systems. It is noteworthy that both SDII and R95p are found to increase significantly over both EC and Bu regions. The projected change of the regional average of SDII and R95p indices are, respectively, $+1.6(+4.9)$ and +2.0 (+9.5) $\mathrm{mm} \mathrm{day}^{-1}$, with percentage change between 15 to $17 \%$, over the $\mathrm{EC}(\mathrm{Bu})$ region.

\section{Projected Changes Of Meiyu-baiu Extreme Rainfall And Associated Synoptic-scale Systems}

We now examine the upper-level synoptic-scale systems associated with EC and Bu extreme rainfall, in the present and the future climate. Here composite maps of v300' for day 0 in the present and future climate simulations are computed. From Fig. 6, it can be clearly seen that there exists a wave train (within $30-45 \mathrm{~N}$ ) with wavelength of about $45^{\circ}$ to $50^{\circ}$ affecting the search regions. Such a wave train is positioned in a way that, a significantly positive v300' signal is influencing just up-stream of the search region, while negative signals are located to its east and west. The mean wave amplitude and anomalous streamfunction at $300 \mathrm{hPa}\left(\Psi 300^{\prime}\right)$ shown in composite maps can also be used to estimate the magnitude of theses waves. Results show that while there is no obvious change for those affecting EC, the mean amplitude of waves influencing the Bu region exhibit weakening in the future. 
v300' composites from lag = -2 to 2 days (Fig. S3) are also computed, so as to better visualize the eastward propagation of wave signals. The strongest positive $\mathrm{v}^{300_{6 h}}$ ' signal of the synoptic-scale wave passes through the search region (on day 0 ) with almost the same phase speed in the present as well as the future climate simulations. Based on two-sided Monte Carlo permutation tests of the phase speed estimated by best fitting maximum signal positions, there is no significant change of the phase speed in these two regions. On the other hand, the background subtropical jet stream is projected to change slightly in its position and intensity (see Fig. S3); projected changes of low-to-mid level and large-scale circulations will be further examined.

We have also examined the amplitude of $\mathrm{v} 300^{\prime}$ affecting the EC and Bu regions. By taking the northernmost and southernmost boundaries of rectangular selection domains (see Section 2) and the longitudinal positions of the $\mathrm{v}^{300}$ ' trough signal, the wave amplitude is computed as the half of the mean difference between the maximum $5 \%$ of positive $v 300$ ' and minimum $5 \%$ of negative $v 300$ ' within such a rectangular domain. The probability density functions of wave amplitudes for day 0 are shown in Fig. 7. Upper-level waves affecting both regions are projected to decrease by about $6 \%$ (or 0.8 (1.0) $\mathrm{ms}^{-1}$ for EC (Bu), passing the $95 \%$ significance level based on one-sided Monte Carlo permutation tests) in the future climate. For both regions, waves with weak-to-intermediate amplitude become more likely to occur, while the stronger waves generally become less likely in the future climate.

In order to investigate the projected changes of low-to-mid level circulation, it is also worthwhile to examine how the anomalous $500 \mathrm{hPa}$ pressure velocity (omg500') and temperature advection at $700 \mathrm{hPa}$ (tempadv700') are modulated. Fig. 8. gives composite maps of omg500' and tempadv700' in the present and future climate simulations. Anomalous upward (downward) motion over the two regions (the upstream positions) becomes weaker in the future climate. Here, changes of regionally averaged omg500' over EC region passes the $90 \%$ significance level (based on one-sided Monte Carlo permutation tests). Anomalous temperature advection is also slightly reduced in both regions, although reduction of the regionally averaged anomalies over both regions do not pass one-sided Monte Carlo permutation tests. Nevertheless, based on quasi-geostrophic analysis (Holton and Hakim, 2012), reduced warm advection should lead to less vigorous upward motion, which is therefore consistent with the weakening of associated upper-level waves.

With a decrease in the intensity of synoptic-scale systems influencing both EC and Bu regions, the projected change of the related precipitation is now analyzed. An extreme precipitation event (extreme case) is identified whenever daily precipitation exceeds R95p over wet days (see Section 2); in particular the contribution of anomalous total precipitation due to extreme precipitation (ext cont $\left._{\text {t }}\right)$ is examined. Fig. 9 shows the composite maps of extreme precipitation contribution (ext cont ), sea level pressure (slp') and $10 \mathrm{~m}$ wind anomalies (wind $10 \mathrm{~m}^{\prime}$ ), based on the present and future climate simulations. Although the associated extreme precipitation contribution is displaced slightly southward within the EC region, ext cont $_{\text {. }}$ is projected to increase under global warming. The area-averaged values of aforementioned precipitation quantities are listed in Table 1. It can be seen that extreme precipitation contribution increases from 4.56 
to 4.82 (6.84 to 7.93 ) $\mathrm{mm} \mathrm{day}^{-1}$ for EC (Bu) in the future climate simulations, consistent with the projected changes for anomalous total precipitation ( $\left.\mathrm{pp}^{\prime}\right)$. More than $90 \%$ (80\%) of regional average pp' over EC $\mathrm{Bu}$ region in the present climate is due to extreme precipitation, and both of these percentages are found to increase due to global warming. Under the future climate, negative sea level pressure anomalies become weaker for $\mathrm{EC}$ region; for $\mathrm{Bu}$, weaker pressure gradients can also be discerned within and to the south of the region. The surface low influencing Bu tends to become broader in the future as well. All of the above show intensification of both anomalous total precipitation and extreme precipitation contribution, despite weakened low-level circulations, under to global warming.

Projected changes of the basic state of the atmospheric general circulation from the AGCM are now examined. Fig. 10 shows the difference of various circulation variables between the future and the present climate simulations. The intense upper-level warming is found south of $30 \mathrm{~N}$ and also north of $45 \mathrm{~N}$, while the intense low-level warming is found around the plateaus (figure not shown). It results in widespread increment of static stability $(\mathrm{N})$ at $700 \mathrm{hPa}$ over northern to northeastern Asia, southern Asia and over western North Pacific, but decrement of $\mathrm{N}$ at $700 \mathrm{hPa}$ over the central of Asia and central-north of China (Fig. 10a). Static stability becomes stronger especially in the northwest of Bu region, generally consistent with more significant weakening of waves affecting the Bu region (Fig. 7). Here, change in baroclinity is further examined by calculating the Eady growth rate:

\section{$\sigma_{E}=0.3098 \cdot \frac{|f|\left|\frac{\partial u}{\partial z}\right|}{N}$}

(Vallis, 2006; Simmonds and Lim, 2009), where $f$ is the Coriolis parameter, $u$ is the zonal wind speed and $N$ is the Brunt-Väisälä frequency. $\sigma_{E}$ is commonly used to reflect the baroclinity by combining the horizontal temperature gradient and the static stability. Although it is still unclear that which level would be more informative (see, e.g. Lim and Simmonds, 2007), $\sigma_{E}$ at $500 \mathrm{hPa}$ will be considered here since its projected changes are similar to but smoother than those at $700 \mathrm{hPa}$. Here, we will consider changes of $\sigma_{E}$ at $500 \mathrm{hPa}$. From Fig. 10b, it can be seen that the seasonal mean $\sigma_{E}$ is projected to decrease over most of the East Asian mid-latitude regions, with the exception of the increment along a zonal belt near $30 \mathrm{~N}$ and the slight increase around the Mongolia (probably due to warming over the Tibetan Plateau). It is noteworthy that upper-level wave trains influencing both regions (as shown in Fig. 6) generally pass through the regions of reduced $\sigma_{E}$, thus consistent with the general weakening of baroclinic systems influencing both EC and Bu. Fig. 10c shows the projected changes of variance of eastward propagating v300' signals. The v300' variance, which reflects the wave amplitudes, is found to decrease over the midlatitudes of the East Asia in the future, compared to the present climate in the MRI simulations. Such decrease of variance is particularly strong around $45-55 \mathrm{~N}$, but otherwise weak in the central and north of China. Regions with reduction of variance generally coincide with those where active upstream trough signals influence both EC and Bu (Fig. 6); this is consistent with the weakening of synoptic-scale waves 
associated with extreme rain cases. At the same time, patterns of reduced variance match those showing a decrease of $\sigma_{\mathrm{E}}$ (Fig.10b), suggesting that the increment of static stability is the main reason of weakening of those synoptic-scale waves.

After examining changes of the basic state, how global warming might affect the $\mathrm{EC}$ and Bu extreme rainfall associated with the synoptic-scale disturbance is now studied. Percentage change of mean rainfall and various extreme precipitation indices per unit degree of lower-tropospheric warming, for each grid box, were computed. The lower-tropospheric temperature is defined as the June to mid-July mean temperature averaged between the surface and $500 \mathrm{hPa}$ level. Fig. 11 shows the probability density function of percentage changes of those indices per unit degree warming within the $E C$ and Bu regions. Changes in SDII, R95p and the average precipitation of extreme cases over both EC and Bu regions generally peak around $7 \% \mathrm{~K}^{-1}$, thus conforming to the $\mathrm{CC}$ relation (see Figs. $11 \mathrm{a}$ and $11 \mathrm{~b}$ ). However, changes of mean precipitation are mostly likely found at $~ 2(6) \% \mathrm{~K}^{-1}$ for EC (Bu) respectively. To further investigate changes of extremes associated with synoptic-scale systems, a similar set of statistics were computed based on wave-related extreme days only. From Fig. 11c, the mean rainfall and SDII probability over EC peak at values less than those in Fig. 11a. In other words, the fractional change of wave-related rainfall per degree warming is less than that for all extreme events, and is likely due to weakening of systems in the EC region. On the other hand, for Bu, changes of the mean rainfall and SDII, as well as R95p, are all consistent with the CC-relation (Fig. 11b). The first two statistics over Bu become larger for wave-related days only (Fig. 11d), which highlights the importance of extremes in contributing to the mean precipitation in Bu. In general, changes of R95p basically follow the CC-relation in both EC and Bu. For the EC region, mean rainfall and SDII do not follow CC-relation for wave-related days only; however, for the Bu region, all extreme indices and the mean rainfall seem to follow the CC-relation. It suggests that weakening of the synoptic-scale systems due to global warming is too modest to modulate the thermodynamic impacts on extreme precipitation; this is probably the reason why the extreme indices still follow the CC-relation.

\section{Discussions And Conclusions}

In this study, we examined the projected change of Meiyu-Baiu extreme precipitation and the associated mid-latitude synoptic-scale weather systems over the EC and Bu regions, based on simulations from the 20-km MRI-AGCM3.2S. The model can capture well the seasonal evolution of extreme rainfall activities associated with the Meiyu-Baiu rainband, albeit with their occurrence overestimated during spring for the EC region. Furthermore, the AGCM can reproduce the relation between wave-like upper-level vwind/streamfunction signals and regional precipitation as seen in observations, in the June-to-mid-July season. A novel wave-selection algorithm was developed to identify upper-level propagating $v$-wind wave signals associated with extreme rainfall. This algorithm was then applied to both present and future climate simulations by the MRI model, so as to infer impacts of global warming on the behavior of these circulation systems. 
Decrease of intensity of these waves influencing both $\mathrm{EC}$ and Bu region was found, with a reduction in their mean amplitudes by about $6 \%$. The corresponding low-to-mid circulation, including vertical velocity, temperature advection and sea-level pressure anomalies, were also weakened in both areas. Indeed, the amplitude of eastward-propagating $\mathrm{v}^{300}$ ' signals in mid latitudes was also projected to be reduced in the model simulations. Such weakening of baroclinic systems is consistent with reduced Eady growth rate, due to increment of static stability over the Eurasian mid-to-high latitude locations. However, extreme precipitation over Bu and EC including that due to upper-level disturbances are projected to intensify in the future climate. Further analysis showed that extreme rainfall will become increasingly important to the $\mathrm{EC}$ and Bu rainfall variability; the former will contribute even more to the rainfall amount expected from these wave-like systems, according to model projections. Intensification of extreme rainfall was likely due to the warmer low-to-mid level background temperature, with scaling broadly consistent with the CC-relation. In summary, the thermodynamic effect seems to play a dominant role in governing changes of EC and Bu extreme precipitation; event though the synoptic-scale disturbances will become weaker in the future climate, the related extreme rainfall still scales with background temperature according to the CC-relation.

It is noticed that MRI-AGCM tends to underestimate early-summer southwesterlies and overestimate springtime precipitation over southeastern China; the model-simulated proportion of wet days during the Meiyu-Baiu season is also greater than that according to TRMM. These biases might be related to the sensitivity of the monsoon rainband evolution to the cumulus parameterization scheme used (e.g. Lee et al., 2008). One possible way to reduce such systematic biases is to implement multi-physics or multimodel ensemble simulations. It will also be instructive to run atmospheric models at convective permitting scales. Ensemble or multi-model ensemble prediction may then be further implemented to minimize individual model biases. Gao et al. (2006) found that model resolutions of $60 \mathrm{~km}$ or higher are needed for accurate simulation of East Asian precipitation; on the other hand, Shi et al. (2018) found that fine resolution is critical only for spatial variability of the general circulation features themselves, but not the response due to climate forcing. Whether the resolution adopted by this AGCM is sufficient to capture the projected changes of extreme precipitation characteristics might need to be further investigated. Finally, since the AGCM is an atmosphere-only model, particular attention should be paid to examine how the absence of air-sea interaction might impact on the simulated monsoon rainfall (see, e.g., Wang et al., 2005).

Using projections by the same AGCM, Chen et al. (2020) found that rainfall associated with each TC system tends to intensify; these systems also tend to move further inland over Asia in the future climate. On the other hand, the same model also projected a reduction of TC frequency south of Japan (see Lui et al. (2018)). Further investigation should be conducted to see how TC-related extreme precipitation over Bu might be modulated in future, in view of these competing effects due to under global warming.

\section{Declarations}


Acknowledgements: The authors would like to thank Dr. Akio Kitoh for generously sharing the MRI-AGCM outputs from the KAKUSHIN Program, and Profs. Edmund Chang and Joong-Bae Ahn for discussions. NCL at the Chinese University of Hong Kong is partially supported by the AXA Research Fund.

\section{References}

Alexander, L.V., and co-authors (2006). Global observed changes in daily climate extremes of temperature and precipitation. Journal of Geophysical Research Atmospheres, 111, 1-22.

https://doi.org/10.1029/2005JD006290

Allen, M. R., and Ingram, W. J. (2002). Constraints on future changes in climate and the hydrologic cycle. Nature, 419(6903). https://doi.org/10.1038/nature01092

Berbery, E. H., and Vera, C. S. (1996). Characteristics of the Southern Hemisphere Winter Storm Track with Filtered and Unfiltered Data. Journal of the Atmospheric Sciences, 53(3), 468-481.

Chang, E. K. M. (1993). Downstream Development of Baroclinic Waves As Inferred from Regression Analysis. Journal of the Atmospheric Sciences, 50(13), 2038-2053.

Chang, E. K. M., and Yu, D. B. (1999). Characteristics of Wave Packets in the Upper Troposphere. Part I: Northern Hemisphere Winter. Journal of the Atmospheric Sciences, 56(11), 1708-1728.

Chen, J., and co-authors (2020): Increasing Exposure of East Asian Inland Regions to Tropical Cyclone Threats in the Past and a Globally Warmed Future Climate, Geophys. Res. Lett., submitted.

Chen, S., and co-authors (2013). Similarity and difference of the two successive V6 and V7 TRMM multisatellite precipitation analysis performance over China. Journal of Geophysical Research: Atmospheres, 118(23), 13,060-13,074. https://doi.org/10.1002/2013jd019964

Chen, T. J. G., and Chang, C. P. (1980). The Structure and Vorticity Budget of an Early Summer Monsoon Trough (Mei-Yu) over Southeastern China and Japan. Monthly Weather Review, 108, 942-953.

Coumou, D., Lehmann, J., and Beckmann, J. (2015). The weakening summer circulation in the Northern Hemisphere mid-latitudes. Science, 348(6232), 324-327. https://doi.org/10.1126/science.1261768

Dee, D. P., and co-authors (2011). The ERA-Interim reanalysis: configuration and performance of the data assimilation system. Quarterly Journal of the Royal Meteorological Society, 137(656), 553-597. https://doi.org/10.1002/qj.828

Ding, Y. (1992). Summer Monsoon Rainfalls in China. Journal of the Meteorological Society of Japan, 70(1B), 373-396.

Ding, Y., and Chan, J. C. L. (2005). The East Asian summer monsoon: an overview. Meteorology and Atmospheric Physics, 89(1), 117-142. https://doi.org/10.1007/s00703-005-0125-z 
Ding, Y., Liu, J., Sun, Y., Liu, Y., He, J., and Song, Y. (2007). A Study of the Synoptic-Climatology of the Meiyu System in East Asia. Chinese Journal of Atmospheric Sciences, 31(6), 1082-1101. (in Chinese).

Ding, Y., and Sikka, D. R. (2006). Synoptic systems and weather. In B. Wang (Ed.), The Asian Monsoon (pp. 131-201). https://doi.org/10.1007/3-540-37722-0_4

Donat, M. G., and co-authors. (2013). Updated analyses of temperature and precipitation extreme indices since the beginning of the twentieth century: The HadEX2 dataset. Journal of Geophysical Research: Atmospheres, 118(5), 2098-2118. https://doi.org/10.1002/jgrd.50150

Donat, M. G., Lowry, A. L., Alexander, L.V., O'Gorman, P. A., and Maher, N. (2016). More extreme precipitation in the world's dry and wet regions. Nature Climate Change, 6(5), 508. https://doi.org/10.1038/nclimate2941

Francis, J. A., and Vavrus, S. J. (2012). Evidence linking Arctic amplification to extreme weather in midlatitudes. Geophysical Research Letters, 39(6). https://doi.org/10.1002/grl.50880

Gao, X., Xu, Y., Zhao, Z., Pal, J. S., and Giorgi, F. (2006). On the role of resolution and topography in the simulation of East Asia precipitation. Theoretical and Applied Climatology, 86(1-4), 173-185. https://doi.org/10.1007/s00704-005-0214-4

Geng, Q., and Sugi, M. (2002). Possible Change of Extratropical Cyclone Activity due to Enhanced Greenhouse Gases and Sulfate Aerosols - Study with a High-Resolution AGCM. Journal of Climate, 16(13), 2262-2274. https://doi.org/10.1175/1520-0442(2003)16<2262:PCOECA>2.0.CO;2

Hawcroft, M. K., Shaffrey, L. C., Hodges, K. I., and Dacre, H. F. (2012). How much Northern Hemisphere precipitation is associated with extratropical cyclones? Geophysical Research Letters, 39(24), 1-6. https://doi.org/10.1029/2012GL053866

Holton, J.R. and Hakim, G.J. (2012). An Introduction to Dynamic Meteorology (5 $5^{\text {th }}$ Edition). Academic Press.

Huffman, G. J., and co-authors (2007). The TRMM Multisatellite Precipitation Analysis (TMPA): QuasiGlobal, Multiyear, Combined-Sensor Precipitation Estimates at Fine Scales. Journal of Hydrometeorology, 8(1), 38-55. https://doi.org/10.1175/jhm560.1

Japan Meteorological Agency (2007). Outline of the operational numerical weather prediction at the Japan Meteorological Agency (Appendix to WMO numerical weather prediction progress report).

Kitoh, A., Ose, T., Kurihara, K., Kusunoki, S., Sugi, M., and Kakushin Team-3 Modeling Group. (2009). Projection of changes in future weather extremes using super-high-resolution global and regional atmospheric models in the KAKUSHIN Program: Results of preliminary experiments. Hydrological Research Letters, 3, 49-53. https://doi.org/10.3178/hrl.3.49 
Lee, D. Y., Tam, C. Y., and Park, C. K. (2008). Effects of multi-cumulus convective ensemble on East Asian summer monsoon rainfall simulation. Journal of Geophysical Research Atmospheres, 113(24), 1-13. https://doi.org/10.1029/2008JD009847

Lenderink, G., and van Meijgaard, E. (2008). Increase in hourly precipitation extremes beyond expectations from temperature changes. Nature Geoscience, 1(8), 511-514.

https://doi.org/10.1038/ngeo262

Li, Y., Lau, N. C., Tam, C. Y., Cheung, H. N., Deng Y. and Zhang, H. (2021). Projected changes in the characteristics of the East Asian summer monsoonal front and their impacts on the regional precipitation. Climate Dynamics, 1-14. https://doi.org/10.1007/s00382-021-05687-y

Lim, E. P., and Simmonds, I. (2007). Southern Hemisphere Winter Extratropical Cyclone Characteristics and Vertical Organization Observed with the ERA-40 Data in 1979-2001. Journal of Climate, 20(11), 2675-2690. https://doi.org/10.1175/JCLI4135.1

Lui, Y. S., Tam, C. Y., and Lau, N. C. (2018). Future changes in Asian summer monsoon precipitation extremes as inferred from 20-km AGCM simulations. Climate Dynamics, 1-17.

https://doi.org/10.1007/s00382-018-4206-3

Mizuta, R., Matsueda, M., Endo, H., and Yukimoto, S. (2011). Future Change in Extratropical Cyclones Associated with Change in the Upper Troposphere. Journal of Climate, 24(24), 6456-6470. https://doi.org/10.1175/2011JCLI3969.1

Mizuta, R., and co-authors (2006). 20-km-Mesh Global Climate Simulations Using JMA-GSM Model Mean Climate States-. Journal of the Meteorological Society of Japan. Ser. II, 84(1), 165-185.

https://doi.org/10.2151/jmsj.84.165

Mizuta, R., and co-authors (2012). Climate Simulations Using MRI-AGCM3.2 with 20-km Grid. Journal of the Meteorological Society of Japan. Ser. II, 90, 233-258. https://doi.org/10.2151/jmsj.2012-a12

Murakami, H., and co-authors (2012). Future Changes in Tropical Cyclone Activity Projected by the New High-Resolution MRI-AGCM. Journal of Climate, 25(9), 3237-3260. https://doi.org/10.1175/JCLI-D-1100415.1

Ninomiya, K., and Akiyama, T. (1992). Multi-scale Features of Baiu, the Summer Monsoon over Japan and the East Asia. Journal of the Meteorological Society of Japan, 70(1B), 467-495.

https://doi.org/10.2151/jmsj1965.70.1b_467

Ninomiya, K., and Shibagaki, Y. (2007). Multi-Scale Features of the Meiyu-Baiu Front and Associated Precipitation Systems. Journal of the Meteorological Society of Japan, 85B, 103-122.

https://doi.org/10.2151/jmsj.85b.103 
Oh, S. G., Park, J. H., Lee, S. H., \& Suh, M. S. (2014). Assessment of the RegCM4 over East Asia and future precipitation change adapted to the RCP scenarios. Journal of Geophysical Research: Atmospheres, 119(6), 2913-2927. https://doi.org/10.1002/2013JD020693

Pall, P., Allen, M. R., and Stone, D. A. (2007). Testing the Clausius-Clapeyron constraint on changes in extreme precipitation under CO2 warming. Climate Dynamics, 28(4), 351-363.

https://doi.org/10.1007/s00382-006-0180-2

Rayner, N. A., and co-authors (2003). Global analyses of sea surface temperature, sea ice, and night marine air temperature since the late nineteenth century. Journal of Geophysical Research, 108(D14). https://doi.org/10.1029/2002jd002670

Röthlisberger, M., Pfahl, S., and Martius, O. (2016). Regional-scale jet waviness modulates the occurrence of midlatitude weather extremes. Geophysical Research Letters, 43(20), 10,989-10,997.

https://doi.org/10.1002/2016GL070944

Sampe, T., and Xie, S.-P. (2010). Large-Scale Dynamics of the Meiyu-Baiu Rainband: Environmental Forcing by the Westerly Jet. Journal of Climate, 23(1), 113-134.

https://doi.org/10.1175/2009JCLI3128.1

Shi, Y., Wang, G., and Gao, X. (2018). Role of resolution in regional climate change projections over China. Climate Dynamics, 51(5-6), 2375-2396. https://doi.org/10.1007/s00382-017-4018-x

Sillmann, J., Kharin, V. V., Zwiers, F. W., Zhang, X., and Bronaugh, D. (2013). Climate extremes indices in the CMIP5 multimodel ensemble: Part 2. Future climate projections. Journal of Geophysical Research Atmospheres, 118(6), 2473-2493. https://doi.org/10.1002/jgrd.50188

Simmonds, I., and Lim, E. P. (2009). Biases in the calculation of Southern Hemisphere mean baroclinic eddy growth rate. Geophysical Research Letters, 36(1), 1-5. https://doi.org/10.1029/2008GL036320

Solomon, S., Qin, D., Manning, M., Averyt, K., and Marquis, M. (2007). Climate change 2007-the physical science basis: Working group I contribution to the fourth assessment report of the IPCC. Cambridge University Press.

Tiedtke, M. (1993). Representation of Clouds in Large-Scale Models. Monthly Weather Review, 121, $3040-3061$.

Trenberth, K. E. (1991). Storm Tracks in the Southern Hemisphere. Journal of the Atmospheric Sciences, 48(19), 2159-2178.

Ulbrich, U., Leckebusch, G. C., and Pinto, J. G. (2009). Extra-tropical cyclones in the present and future climate: a review. Theoretical and Applied Climatology, 96(1-2), 117-131.

https://doi.org/10.1007/s00704-008-0083-8 
Utsumi, N., Kim, H., Kanae, S., and Oki, T. (2016). Which weather systems are projected to cause future change in mean and extreme precipitation in CMIP5 simulations? Journal of Geophysical Research: Atmospheres, 121, 10522-10537. https://doi.org/10.1002/2016JD025137.

Vallis, G.K. (2006). Atmospheric and Oceanic Dynamics: Fundamentals and Large-Scale Circulation. Cambridge University Press.

Wang, B., and Lin, H. (2002). Rainy season of the Asian-Pacific summer monsoon. Journal of Climate, 15(4), 386-398.

Wang, B., Ding, Q., Fu, X., Kang, I. S., Jin, K., Shukla, J., and Doblas-Reyes, F. (2005). Fundamental challenge in simulation and prediction of summer monsoon rainfall. Geophysical Research Letters, 32(15). https://doi.org/10.1029/2005GL022734

Wang, X. L., Swail, V. R., and Zwiers, F. W. (2006). Climatology and Changes of Extratropical Cyclone Activity: Comparison of ERA-40 with NCEP-NCAR Reanalysis for 1958-2001. Journal of Climate, 19(13), 3145-3166. https://doi.org/10.1175/JCLI3781.1

Westra, S., Alexander, L.V., and Zwiers, F. W. (2013). Global Increasing Trends in Annual Maximum Daily Precipitation. Journal of Climate, 26(11), 3904-3918. https://doi.org/10.1175/JCLI-D-12-00502.1

Yukimoto, S., and co-authors (2011). Meteorological Research Institute-Earth System Model Version 1 (MRI-ESM1) - Model Description. Technical Report of the Meteorological Research Institute, 64.

Zhao, T., and Yatagai, A. (2014). Evaluation of TRMM 3B42 product using a new gauge-based analysis of daily precipitation over China. International Journal of Climatology, 34(8), 2749-2762.

https://doi.org/10.1002/joc.3872

\section{Tables}

Table 1. Future minus present climate values of day 0 anomalous precipitation and contribution due to extreme precipitation ( $\mathrm{mm}$ day $^{-1}$ ), averaged over Eastern China and the Baiu region. See text for details.

\begin{tabular}{|c|c|c|c|c|c|c|}
\hline & \multicolumn{3}{|c|}{ Eastern China } & \multicolumn{3}{|c|}{ Baiu rainband } \\
\hline & $\mathrm{pp}^{\prime}$ & ext $_{\text {cont }}$ & $\%$ of ext $t_{\text {cont }}$ in $\mathrm{pp}^{\prime}$ & $\mathrm{pp}^{\prime}$ & ext $_{\text {cont }}$ & $\%$ of ext ${ }_{\text {cont }}$ in $\mathrm{pp}^{\prime}$ \\
\hline present & 5.06 & 4.56 & $90 \%$ & 8.31 & 6.84 & $82 \%$ \\
\hline future & 5.07 & 4.82 & $95 \%$ & 9.39 & 7.93 & $84 \%$ \\
\hline change & 0.01 & 0.26 & $+5 \%$ & 1.08 & 1.09 & $+2 \%$ \\
\hline
\end{tabular}

\section{Figures}




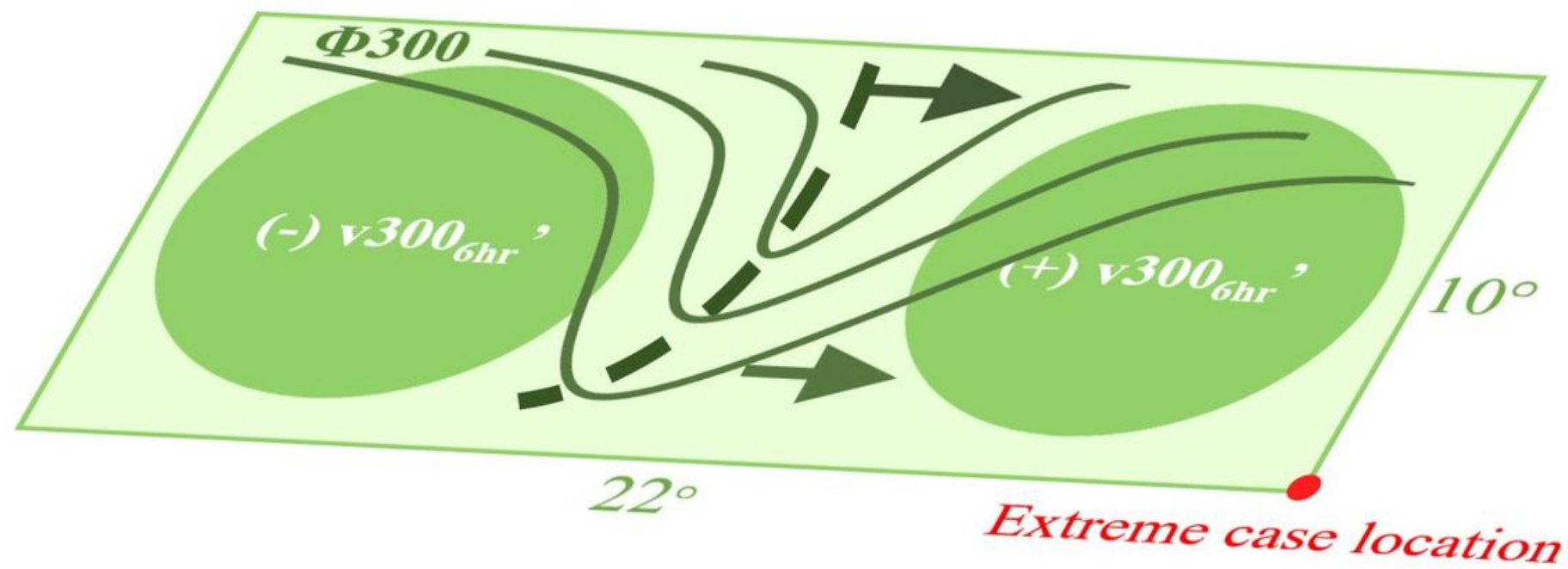

Figure 1

Schematic diagram for identifying upper-level synoptic-scale waves associated with extreme rainfall events. See text for details.
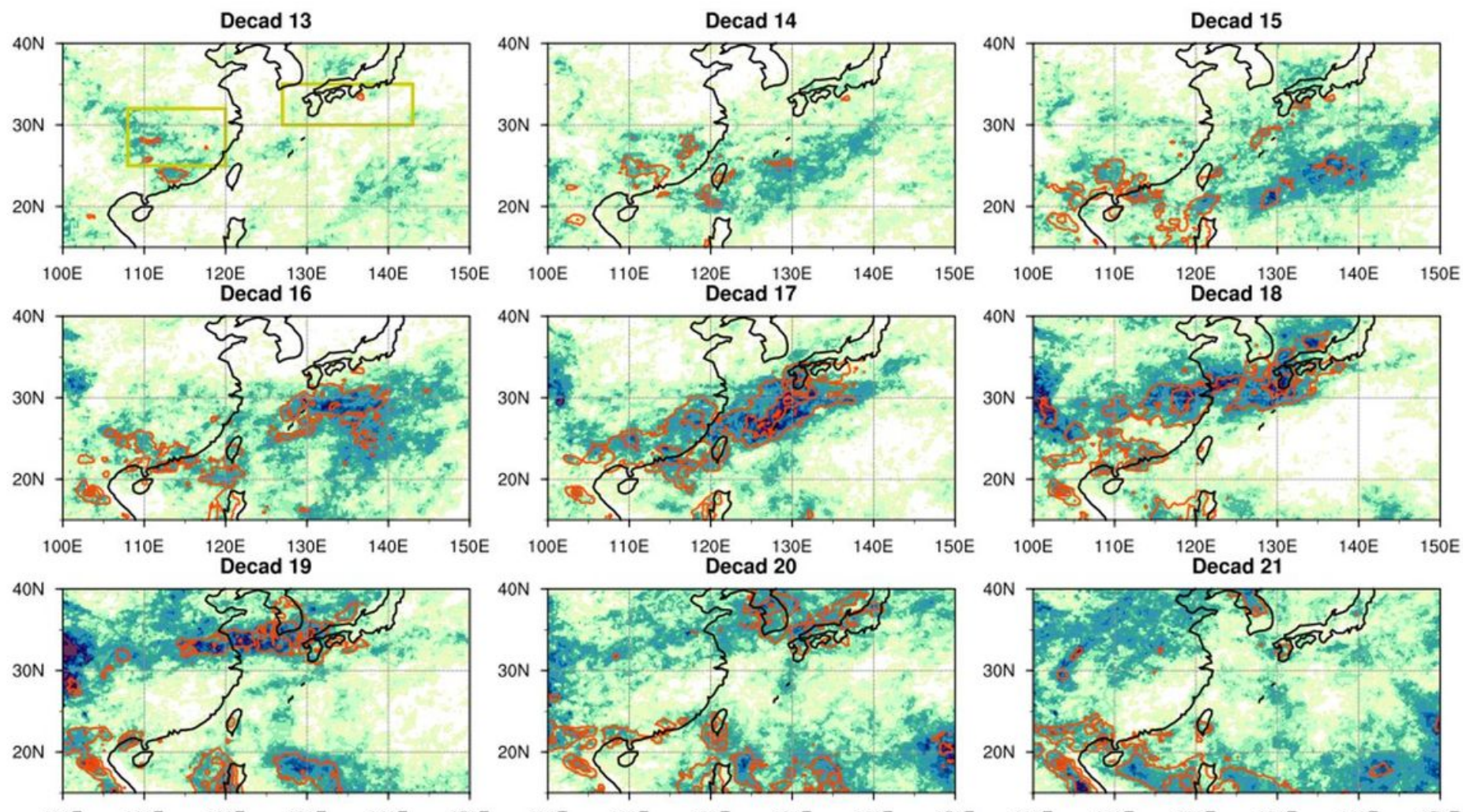

100E $\quad$ 110E 120

$\begin{array}{llllllllllll}0.01 & 0.02 & 0.03 & 0.04 & 0.05 & 0.06 & 0.07 & 0.08 & 0.09\end{array}$

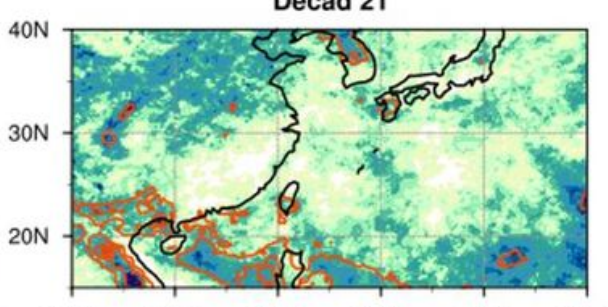

$\begin{array}{lll}0.1 & 0.11 & 0.12\end{array}$

Figure 2 
Climatological decad-mean probability of occurrence of extreme cases from the 13th to 21 st decad based on TRMM3B42v7. Orange contours (in intervals of $5 \mathrm{~mm}$ day-1, for values greater than $10 \mathrm{~mm}$ day-1 only) represent climatological decad-mean precipitation rate. See text for details. Note: The designations employed and the presentation of the material on this map do not imply the expression of any opinion whatsoever on the part of Research Square concerning the legal status of any country, territory, city or area or of its authorities, or concerning the delimitation of its frontiers or boundaries. This map has been provided by the authors.
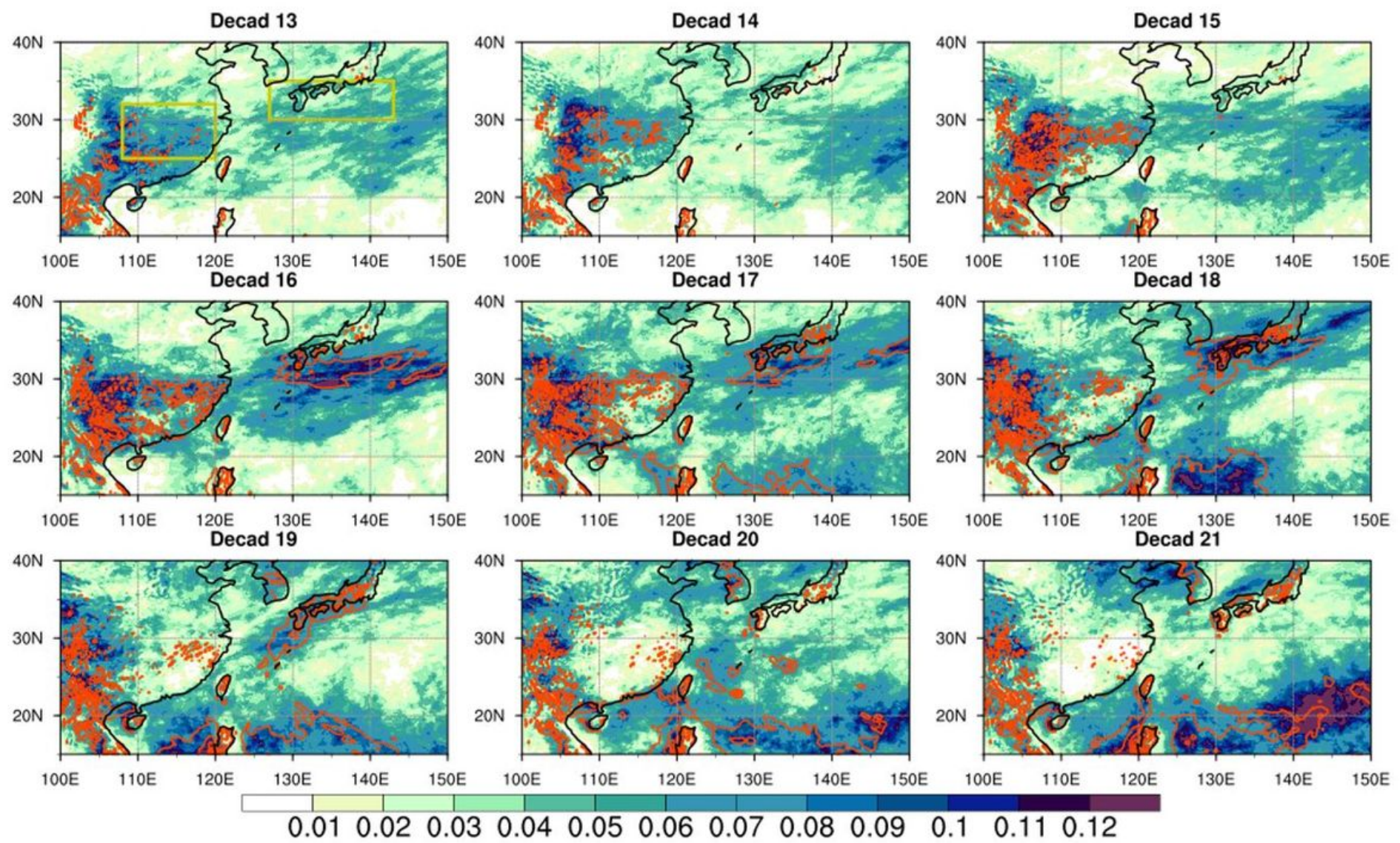

\section{Figure 3}

As in Fig.2, except for MRI-AGCM3.2S simulations. Note: The designations employed and the presentation of the material on this map do not imply the expression of any opinion whatsoever on the part of Research Square concerning the legal status of any country, territory, city or area or of its authorities, or concerning the delimitation of its frontiers or boundaries. This map has been provided by the authors. 
(a) EC, TRMM

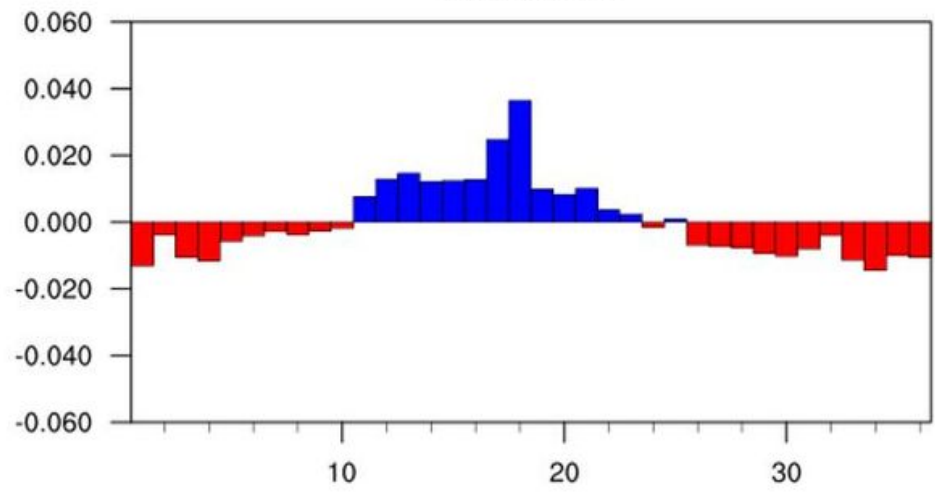

(c) EC, MRI-AGCM

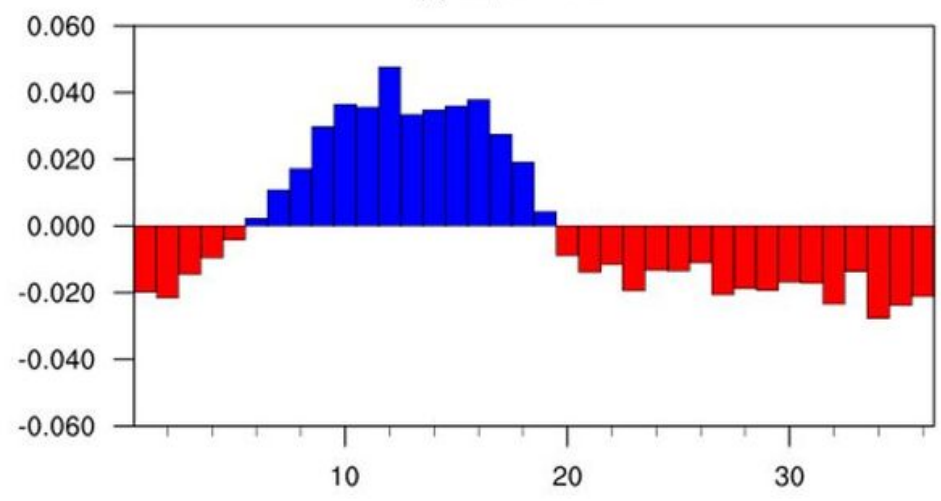

(b) Bu, TRMM

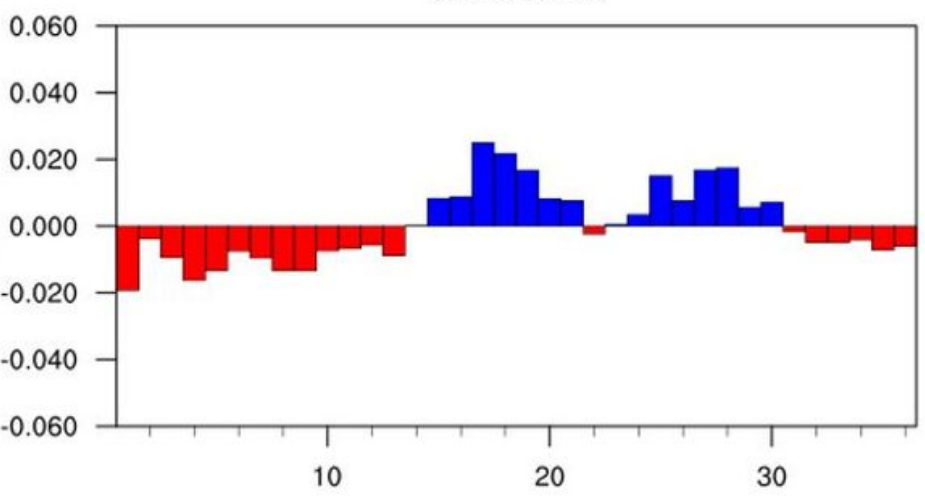

(d) Bu, MRI-AGCM

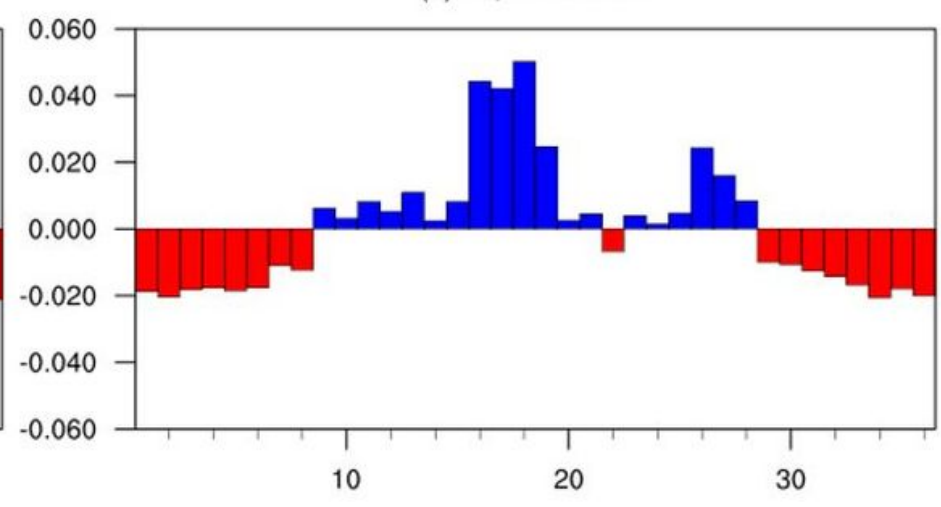

\section{Figure 4}

Deviation of the decad-mean from annual-mean probability of occurrence of extreme rainfall cases averaged over $(a, c)$ Eastern China (25-32N, 108-120E) and (b, d) Baiu rainband (30-35N, 127-143E), based on (a, b) TRMM3B42v7 and (c, d) MRI-AGCM3.2S climatology.
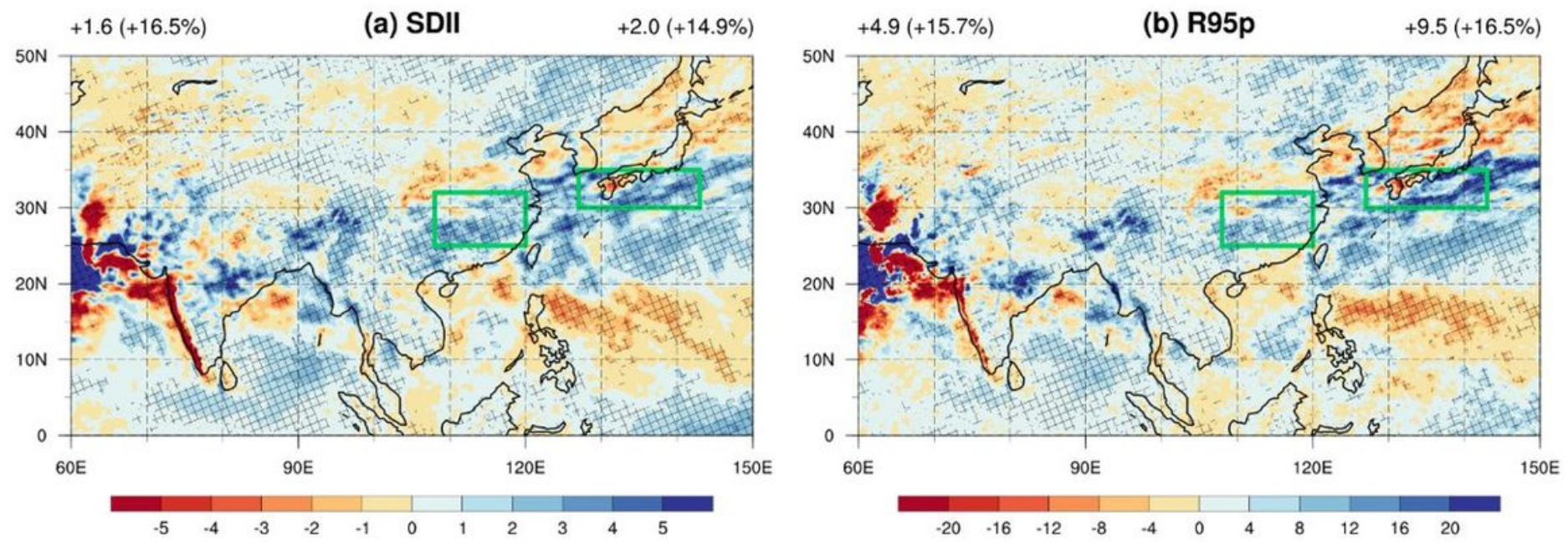

\section{Figure 5}

Future minus present climate (a) SDII (units: mm day-1), and (b) R95p (units: mm day-1) based on MRIAGCM3.2S outputs from June to mid-July. Values and percentage changes averaged over the Eastern 
China (25-32N, 108-120E) and Baiu rainband (30-35N, 127-143E) are shown in upper left and right, respectively. Cross-hatches indicate values passing the $90 \%$ significance level according to the two-sided Monte Carlo permutation test. Note: The designations employed and the presentation of the material on this map do not imply the expression of any opinion whatsoever on the part of Research Square concerning the legal status of any country, territory, city or area or of its authorities, or concerning the delimitation of its frontiers or boundaries. This map has been provided by the authors.
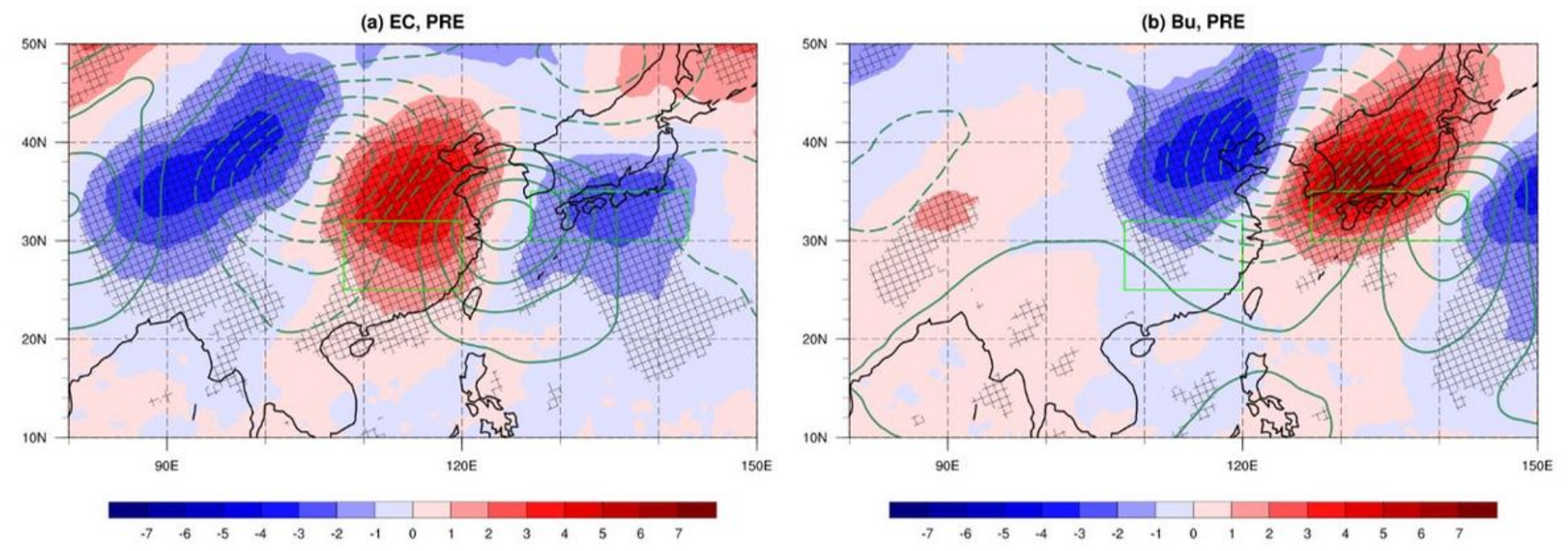

(c) EC, FUT

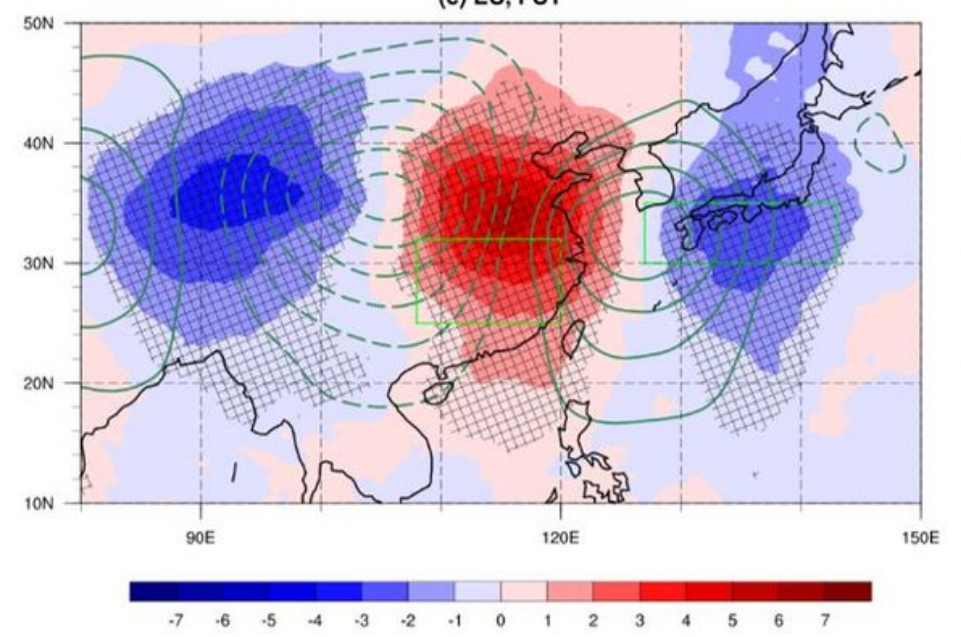

(d) Bu, FUT

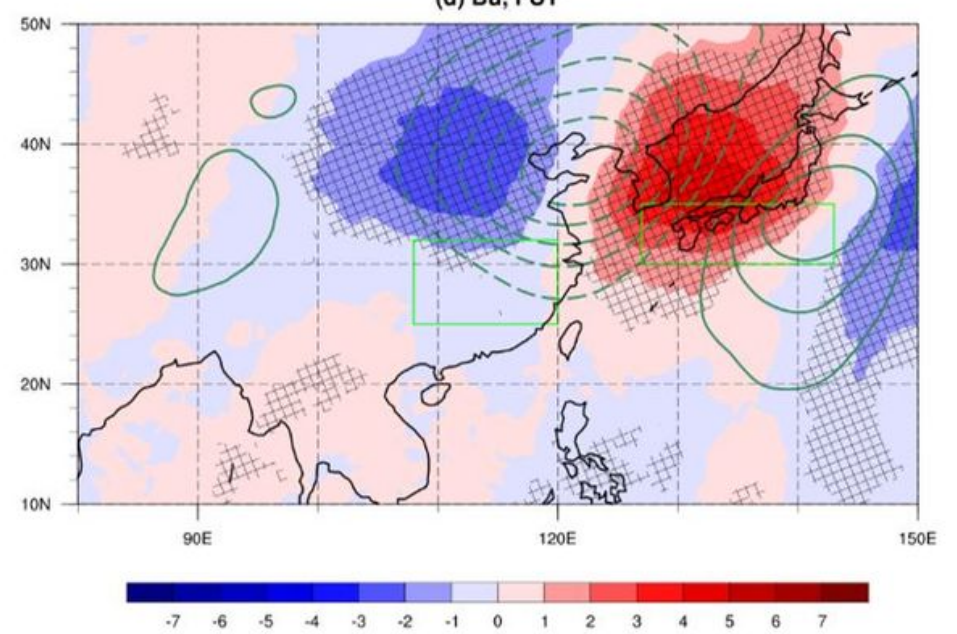

\section{Figure 6}

Day 0 composite $300 \mathrm{hPa}$ v-wind (shading; units: $\mathrm{m} \mathrm{s}-1$ ) and streamfunction anomalies (contours in intervals of $2 \times 106 \mathrm{~m} 2 \mathrm{~s}-1$; dashed and solid contours representing negative and positive values, with zero contours omitted) for (a, c) Eastern China (25-32N, 108-120E) and (b, d) Baiu rainband (30-35N, 127$143 \mathrm{E})$ extreme rainfall events identified in the June-to-mid-July season, for $(a, b)$ present and $(c, d)$ future climate MRI-AGCM3.2S simulations. Cross-hatches indicate v-wind anomalies passing the $90 \%$ significance level. Note: The designations employed and the presentation of the material on this map do not imply the expression of any opinion whatsoever on the part of Research Square concerning the legal 
status of any country, territory, city or area or of its authorities, or concerning the delimitation of its frontiers or boundaries. This map has been provided by the authors.

(a) EC

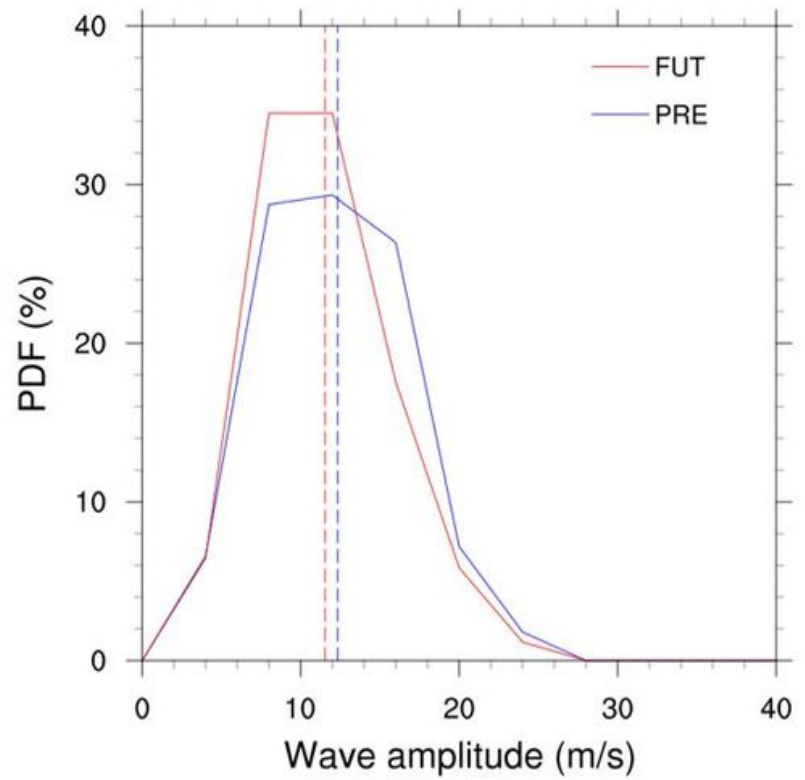

(b) $\mathrm{Bu}$

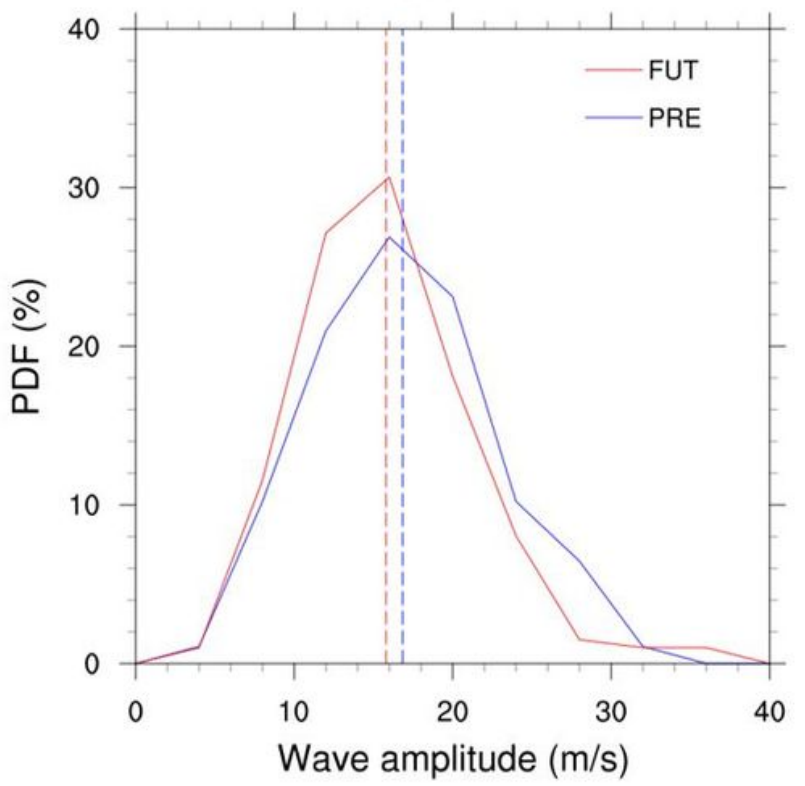

\section{Figure 7}

Present (blue) and the future climate (red) probability density function of wave amplitude based on data for "day 0" over (a) Eastern China (a) (25-32N, 108-120E) and (b) Baiu rainband (30-35N, 127-143E), based on MRI-AGCM3.2S outputs from June to mid-July. Vertical red and blue dashed line represent mean wave amplitude for "day 0 " in the present and future climate respectively. 
(a) EC, PRE

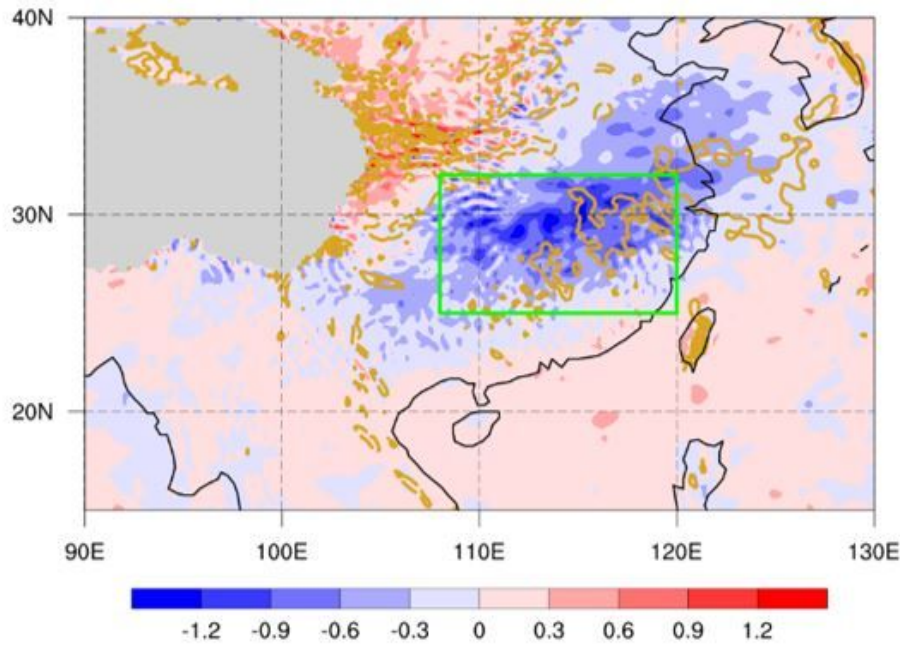

(c) EC, FUT

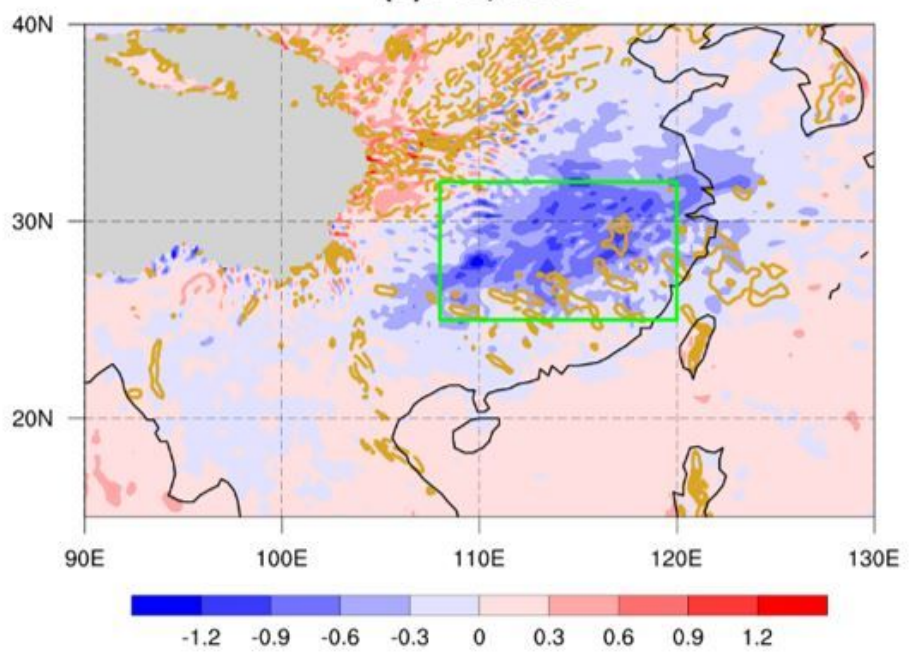

(b) Bu, PRE

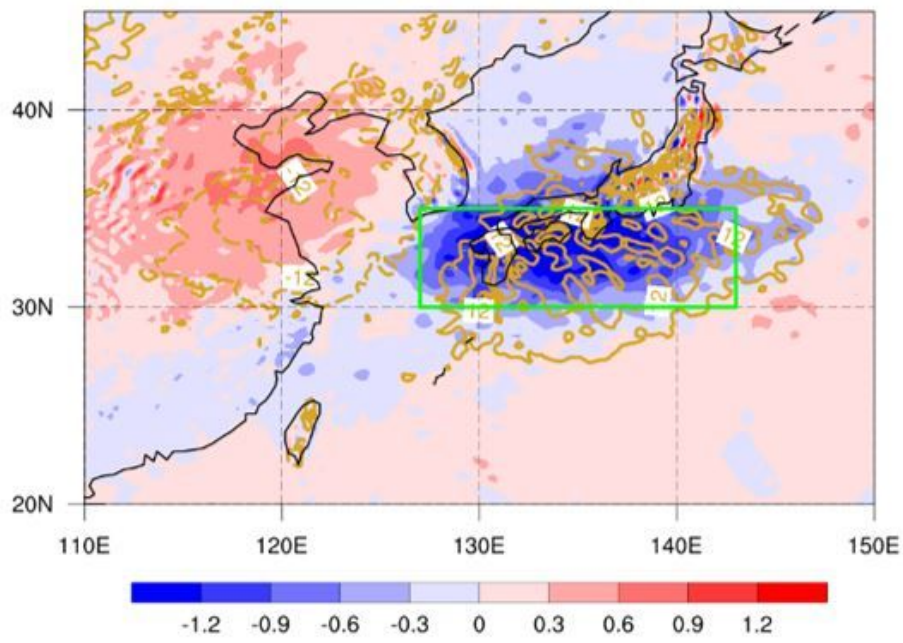

(d) Bu, FUT

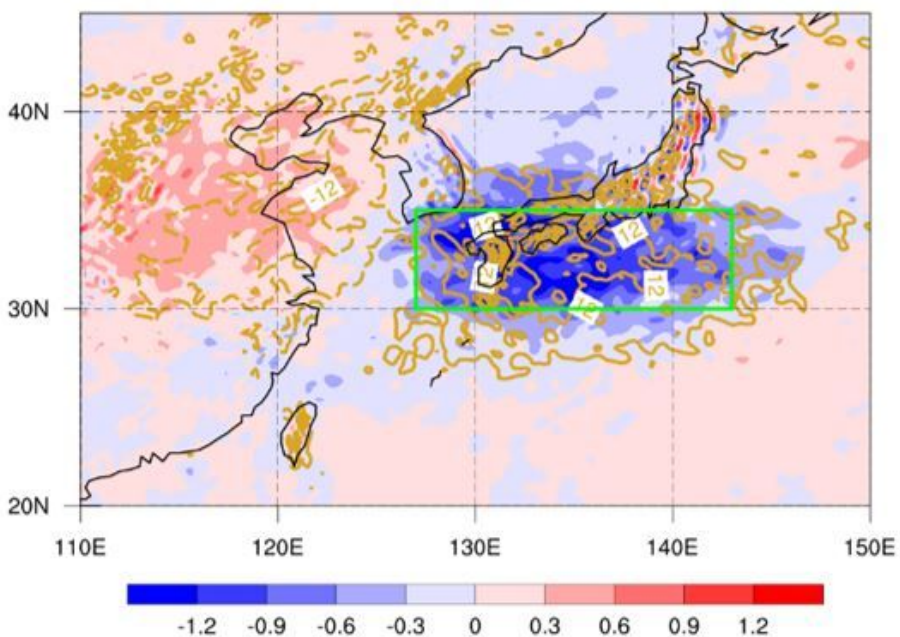

\section{Figure 8}

As in Fig. 6, except for 500hPa pressure velocity (shading; units: Pa s-1) and 700hPa temperature advection anomalies (contour; units: $10-5 \mathrm{~K} \mathrm{~s}-1$ ). Note: The designations employed and the presentation of the material on this map do not imply the expression of any opinion whatsoever on the part of Research Square concerning the legal status of any country, territory, city or area or of its authorities, or concerning the delimitation of its frontiers or boundaries. This map has been provided by the authors. 
(a) EC, PRE

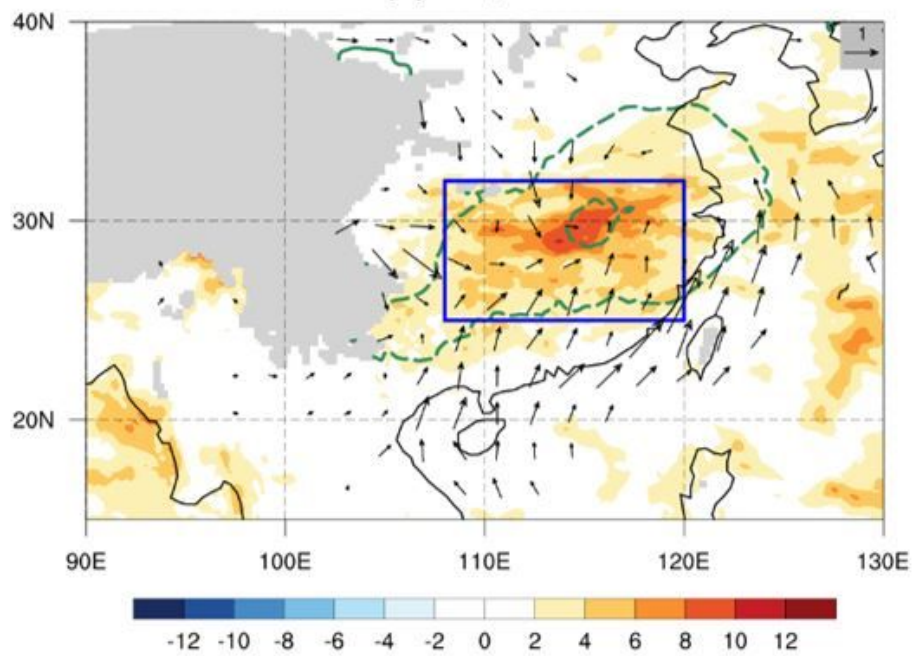

(c) EC, FUT

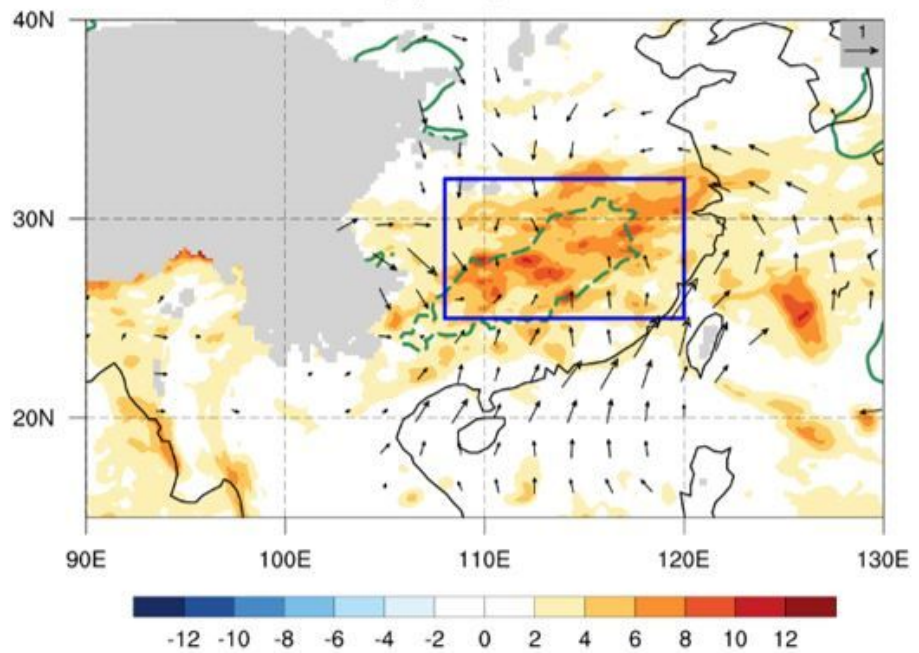

(b) Bu, PRE

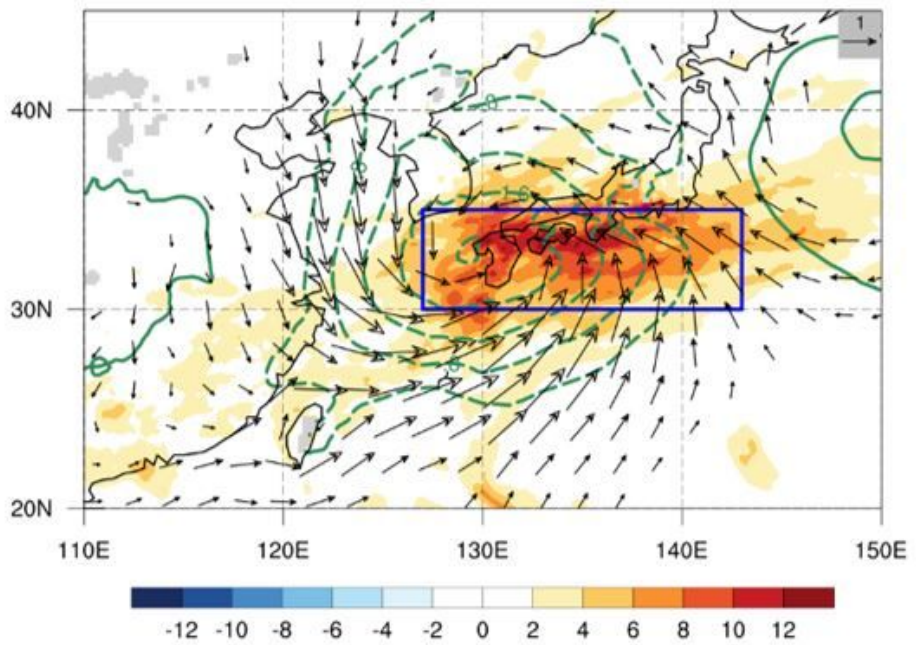

(d) Bu, FUT

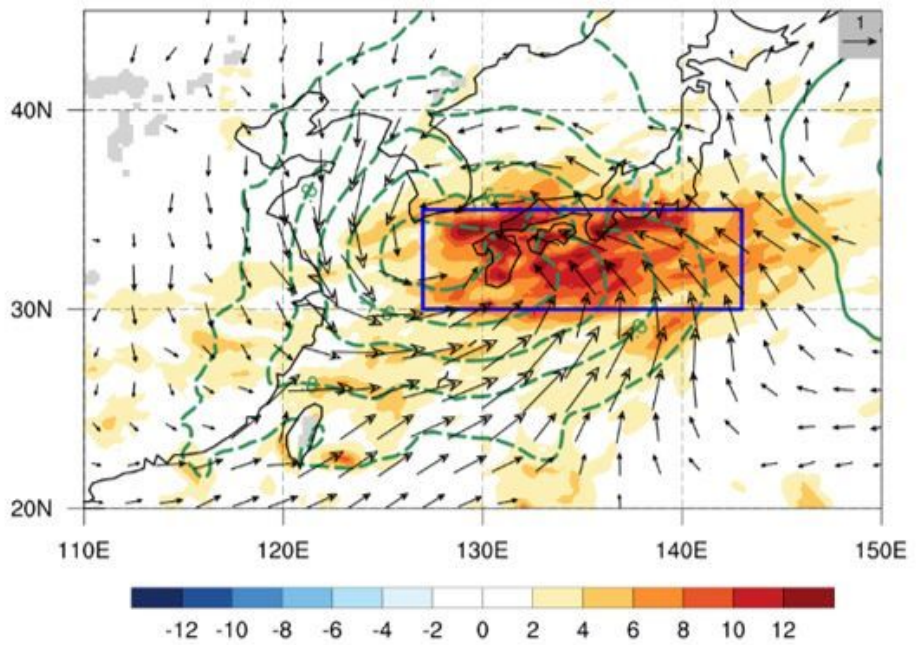

Figure 9

As in Fig.6, except for extcont (shading; units: mm day-1), sea-level pressure (contour; units: hPa) and $10 \mathrm{~m}$ wind (see scale arrow at top right; units: $\mathrm{m} \mathrm{s}-1$ ). See text for details. Note: The designations employed and the presentation of the material on this map do not imply the expression of any opinion whatsoever on the part of Research Square concerning the legal status of any country, territory, city or area or of its authorities, or concerning the delimitation of its frontiers or boundaries. This map has been provided by the authors. 
(a) $\mathrm{N}(700 \mathrm{hPa})$

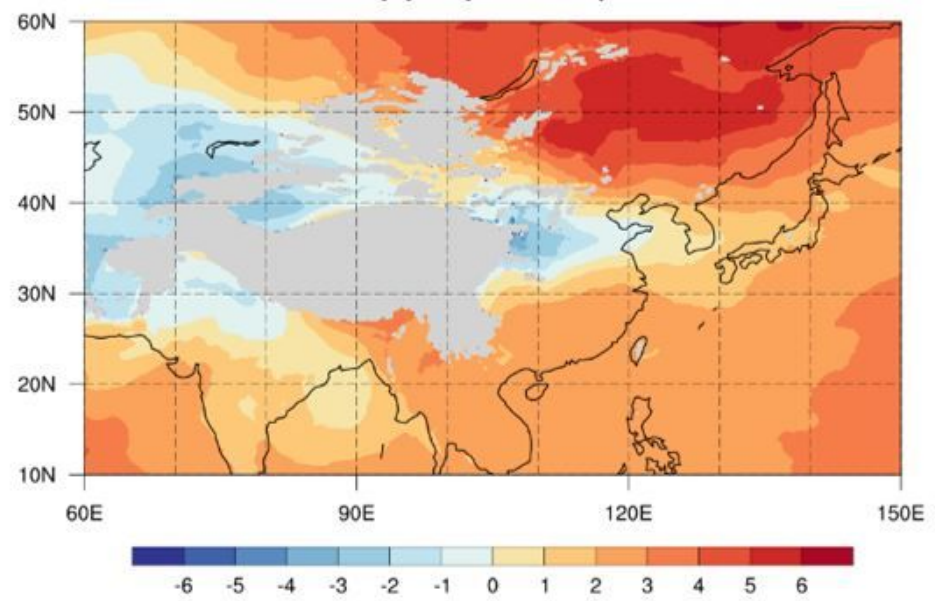

(b) $\sigma_{\mathrm{E}}(500 \mathrm{hPa})$

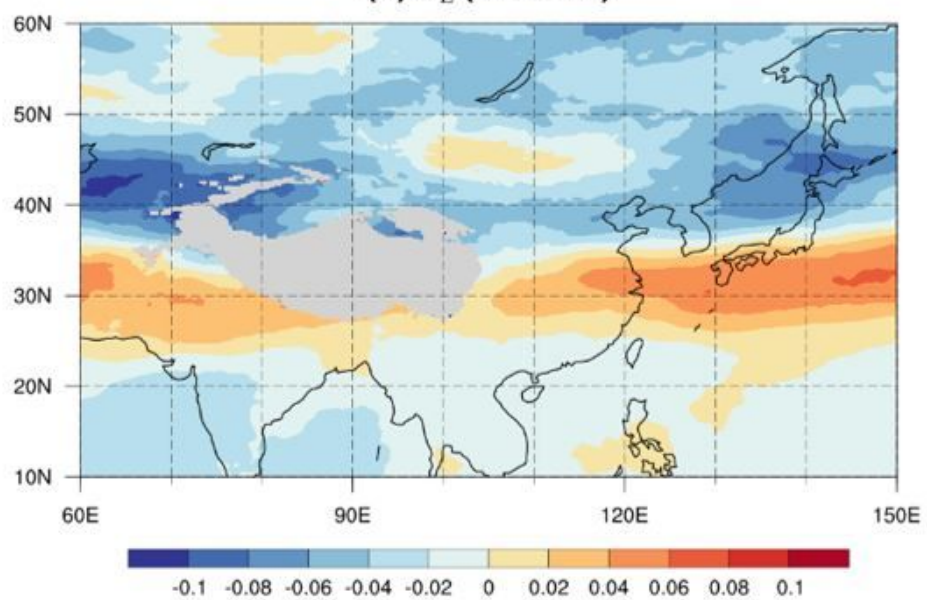

(c) $\operatorname{var}\left({\left.\mathrm{v} 300^{\prime}\right)}^{\prime}\right.$

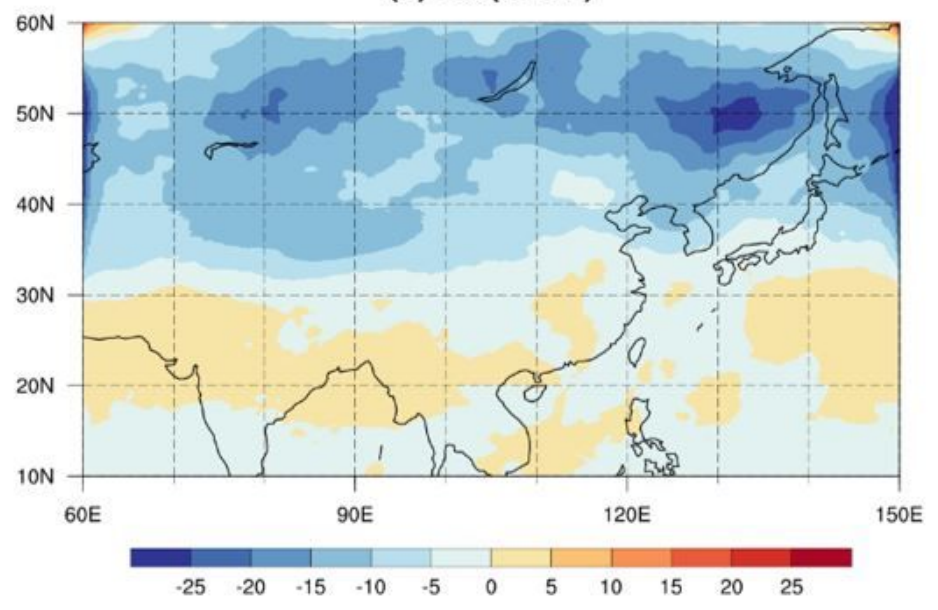

\section{Figure 10}

Future minus present climate values of (a) 700 hPa Brunt-Väisälä frequency (units: 10-4 s-1), (b) 500hPa Eady growth rate (units: day-1) and (c) $300 \mathrm{hPa}$ variance of v-wind anomalies (units: m2 s-2) due to eastward-propagating signals only from June to mid-July based on MRI-AGCM simulations. Note: The designations employed and the presentation of the material on this map do not imply the expression of any opinion whatsoever on the part of Research Square concerning the legal status of any country, territory, city or area or of its authorities, or concerning the delimitation of its frontiers or boundaries. This map has been provided by the authors. 
(a) EC, June to mid-July

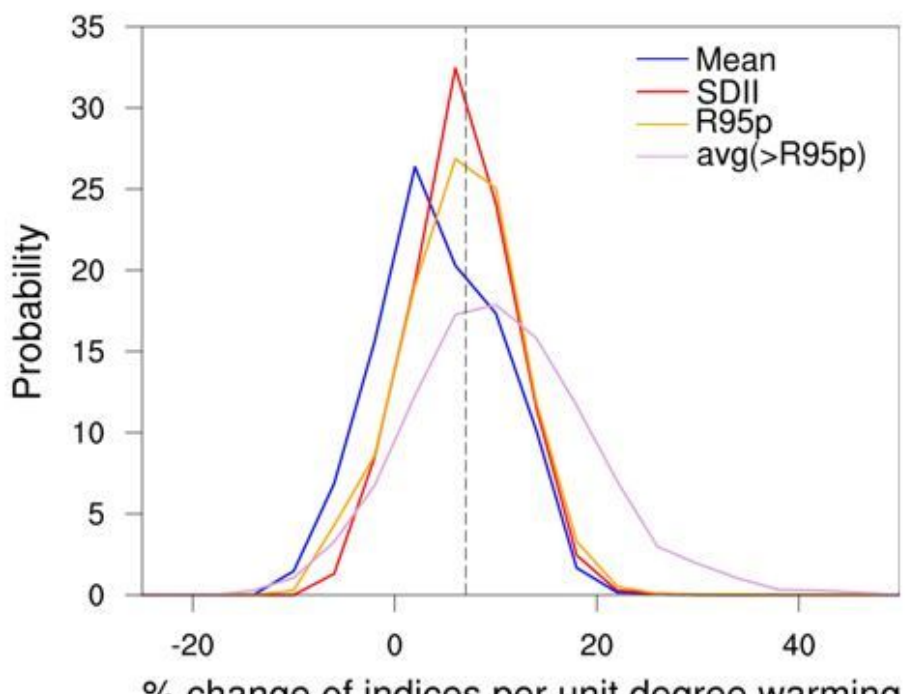

$\%$ change of indices per unit degree warming

(c) EC, wave-related days

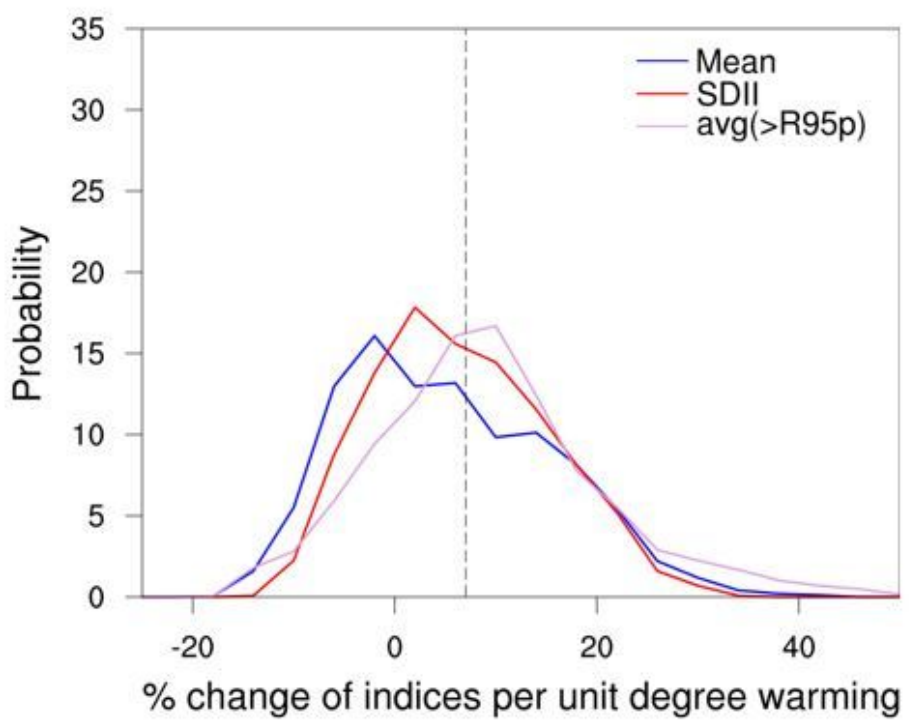

(b) Bu, June to mid-July

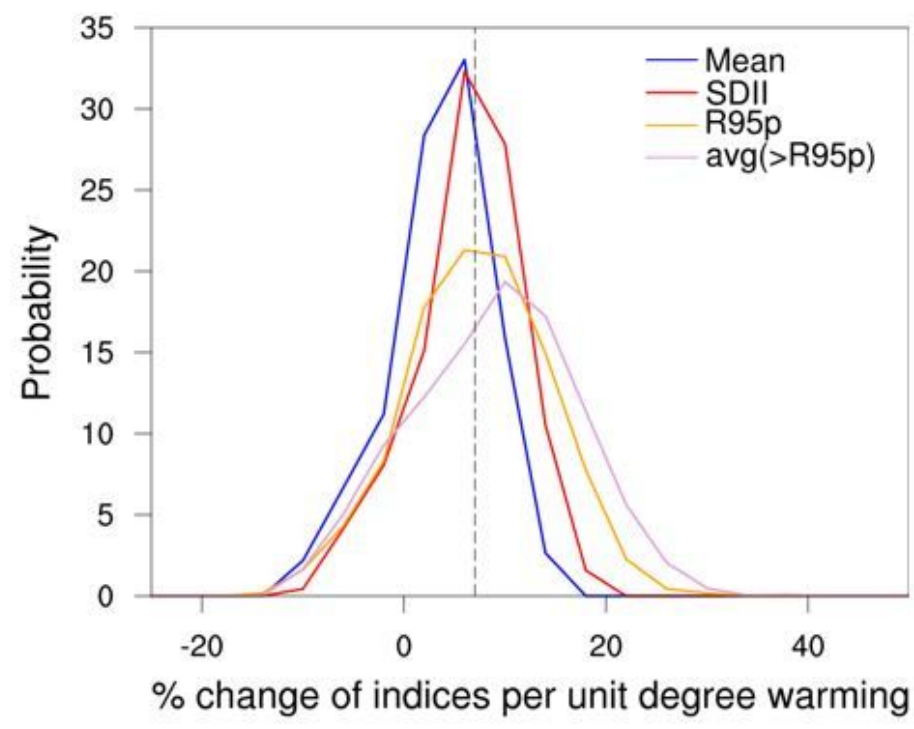

(d) Bu, wave-related days

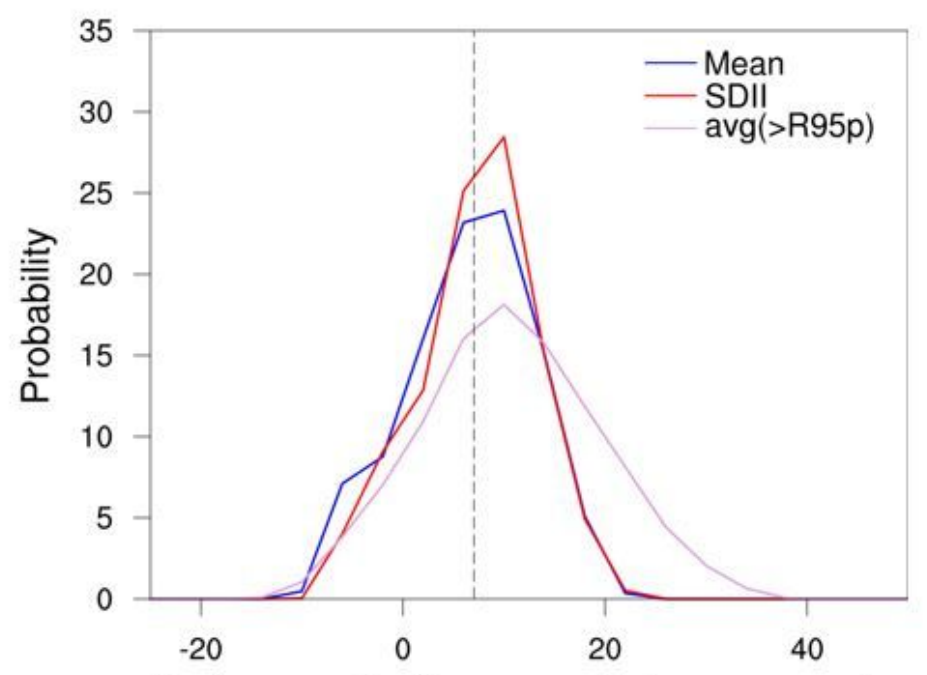

$\%$ change of indices per unit degree warming

\section{Figure 11}

Probability distribution of percentage changes in time mean precipitation rates (blue), SDII (red), averaged precipitation rates for extreme cases (violet) per oC of warming in the lower-to-mid troposphere, computed for $(a, b)$ June-to-mid-July season, and (c, d) extreme rain days associated with synoptic-scale waves only, over (a, c) Eastern China (25-32N, 108-120E) and (b, d) Baiu rainband (30-35N, 127-143E). Also shown are changes in R95p (orange) for the June-to-mid-July period. The vertical dashed line represents the change of $7 \% / \mathrm{oC}$ expected from the CC-relation. See text for details. 


\section{Supplementary Files}

This is a list of supplementary files associated with this preprint. Click to download.

- figs1a.jpg

- figs1b.jpg

- figs1c.jpg

- figs2.jpg

- figs3a.jpg

- figs3b.jpg 